\title{
Circulating extracellular vesicles from patients with breast cancer enhance migration and invasion via a Src-dependent pathway in MDA-MB-231 breast cancer cells
}

\author{
JAVIER RAMÍREZ-RICARDO ${ }^{1}$, ELIZABETH LEAL-ORTA ${ }^{1}$, ELIA MARTÍNEZ-BAEZA ${ }^{1}$, \\ CARLOS ORTIZ-MENDOZA ${ }^{2}$, FERNANDO BRETON-MORA ${ }^{3}$, ANALY HERRERA-TORRES ${ }^{4}$, \\ IRMA ELIZALDE-ACOSTA ${ }^{4}$, PEDRO CORTES-REYNOSA ${ }^{1}$, \\ ROCIO THOMPSON-BONILLA ${ }^{4}$ and EDUARDO PEREZ SALAZAR ${ }^{1}$
}

\author{
${ }^{1}$ Departament of Cell Biology, CINVESTAV-IPN, Mexico City 07360; ${ }^{2}$ General Hospital Tacuba-ISSSTE, Mexico City 11410; \\ ${ }^{3}$ General Hospital Dr. Fernando Quiroz-ISSSTE, Mexico City 01140; ${ }^{4}$ First October Regional Hospital-ISSSTE, \\ Mexico City 07760, Mexico
}

Received December 2, 2019; Accepted May 15, 2020

DOI: $10.3892 / \mathrm{mmr} .2020 .11259$

\begin{abstract}
Triple negative breast cancer (TNBC) is a breast cancer subtype associated with high rates of metastasis, heterogeneity, drug resistance and a poor prognosis. Extracellular vesicles (EVs) are vesicles of endosomal and plasma membrane origin, and are secreted by healthy and cancer cells. In cancer, EVs contribute to tumor progression by mediating escape from the immune system surveillance, and are involved in extracellular matrix degradation, invasion, angiogenesis, migration and metastasis. Furthermore, EVs have been identified in several human fluids. However, the role of EVs from patients with breast cancer in the migration and invasion of human breast cancer cells is not fully understood. The present study investigated whether EVs isolated from Mexican patients with breast cancer can induce cellular processes related to invasion in breast cancer. Moreover, plasma fractions enriched in EVs and deprived of platelet-derived EVs obtained from blood samples of 32 Mexican patients with biopsy-diagnosed breast cancer at different clinical stages who had not received treatment were analyzed. Furthermore, one control group was included, which consisted of 20 Mexican healthy females. The present results demonstrated that EVs from women with breast cancer promote migration and invasion, and increase matrix metalloproteinase (MMP)-2 and MMP-9 secretion in TNBC MDA-MB-231 cells. In addition, it was found that EVs from patients with breast cancer induced Src and focal adhesion kinase activation, and focal adhesions assembly with an
\end{abstract}

Correspondence to: Dr Eduardo Perez Salazar, Departament of Cell Biology, CINVESTAV-IPN, Avenida Instituto Politécnico Nacional 2508, Mexico City 07360, Mexico

E-mail: eduardo.perez@cinvestav.mx

Key words: extracellular vesicles, breast cancer, migration, invasion, focal adhesion kinase, Src, MDA-MB-231 increase in focal adhesions number, while the migration and invasion was dependent on Src activity. Collectively, EVs from Mexican patients with breast cancer induce migration and invasion via a Src-dependent pathway in TNBC MDA-MB-231 cells.

\section{Introduction}

Breast cancer is the most common type of cancer in women worldwide, and is the second leading cause of cancer-associated mortality (1-3). Triple negative breast cancer (TNBC) is a breast cancer subtype associated with high rates of metastasis, heterogeneity, drug resistance and a poor prognosis. The absence of estrogen and progesterone receptors, and low expression of Her-2/neu characterizes TNBC. Moreover, the incidence of TNBC is continuously increasing in young women (4-6).

Extracellular vesicles (EVs) are vesicles derived from membranes that are secreted by healthy and cancer cells, and mediate a variety of biological functions. EVs are classified into two groups according to their origin and size: Exosomes (30-100 nm) and microvesicles (100-1,000 nm) (7). Exosomes are a homogeneous group of vesicles that originate from multivesicular bodies, while microvesicles are a heterogeneous population derived from the plasma membrane during membrane blebbing (8). Furthermore, EVs derived from tumor cells express phosphatidylserine (PS) on their membrane surfaces, and these EVs express higher levels of PS compared with EVs from healthy cells (9-11). Therefore, the quantification of PS in tumor-derived EVs is proposed as a biomarker of tumor progression $(12,13)$.

In cancer, cells are able to transfer nucleic acids, chemokine receptors, growth factor receptors and functional transcription factors via the secretion and uptake of EVs (14). Moreover, cells associated with stroma and tumor cells release EVs that mediate a variety of processes related to cancer progression, including migration, invasion, angiogenesis, evasion of immune response, resistance to drugs and extracellular 
matrix (ECM) degradation (14-16). EVs are present in human fluids, including lymph, urine, breast milk, saliva, amniotic fluid, blood and malignant ascites. In addition, in patients with gastric or breast cancer, the number of EVs circulating is higher compared with healthy controls, and these have been associated with poor prognosis (8,17-19).

Matrix metalloproteinases (MMPs) are a family of proteases that are categorized into different types based on their substrate specificity and sequence characteristics $(20,21)$. Furthermore, MMPs are endopeptidases, which are zinc-dependent and are able to degrade all ECM components. In cancer, MMPs participate in tumor progression by mediating expansion, angiogenesis and invasion via the basement membrane (BM) and interstitial matrices (20). Moreover, cancer progression is associated with upregulation and secretion of MMP-2 (gelatinase A) and MMP-9 (gelatinase B), as malignant tumors overexpress these MMPs, which degrade type IV collagen, which is the most abundant component of BM $(20,22,23)$.

Focal adhesions are the structures on which integrin receptors mediate the adhesion between the actin cytoskeleton and ECM, which are important for a variety of cellular components, including scaffolding proteins, GTPases, phosphatases and kinases $(24,25)$. Moreover, one component of focal adhesions is the focal adhesion kinase (FAK), which is a $125 \mathrm{kDa}$ protein tyrosine kinase that is activated by a variety of agonists, including free fatty acids (26-28). FAK has been implicated in the regulation of cell spreading, differentiation, proliferation, apoptosis, migration, invasion, survival and angiogenesis (29-31). Furthermore, activation of FAK occurs via its autophosphorylation at tyrosine (Tyr)-397, which creates a binding site for the Src kinase and other downstream effectors. Moreover, FAK-Src complex formation is mediated via the Src Homology 2 (SH2) domain of Src and its formation leads to Src activation. Subsequently, Src phosphorylates FAK at Tyr-576 and Tyr-577, which are localized in the activation domain, and their phosphorylation induces maximal FAK kinase activity $(31,32)$.

The present results demonstrated that EVs isolated from the plasma of Mexican women with breast cancer promoted MMP-2 and MMP-9 secretion, Src and FAK activation, assembly of focal adhesions, and the migration and invasion of TNBC MDA-MB-231 cells

\section{Materials and methods}

Materials. BD Matrigel ${ }^{\mathrm{TM}}$ was purchased from BD Biosciences. Hoechst dye was obtained from Santa Cruz Biotechnology, Inc. CellMask $^{\mathrm{TM}}$ Orange plasma membrane stain was obtained from Invitrogen (Thermo Fisher Scientific, Inc.). Tetramethylrhodam ine (TRITC)-conjugated phalloidin, mitomycin C, Annexin V and Triton $^{\mathrm{TM}}$ X-100 were from Sigma-Aldrich (Merck KGaA). PP2 and PP3 were from Merck KGaA.

Cell culture. MDA-MB-231 and MCF-7 breast cancer cells were obtained from the American Type Culture Collection (ATCC) and cultured in DMEM (Gibco; Thermo Fisher Scientific, Inc.), with 5\% FBS (ByProductos), $3.7 \mathrm{~g} / 1$ sodium bicarbonate and antibiotics under a humidified atmosphere with $5 \% \mathrm{CO}_{2}$ and $95 \%$ air at $37^{\circ} \mathrm{C}$.
Human mammary non-tumorigenic epithelial cells (MCF12A) were obtained from ATCC and cultured in DMEM/F12 medium (Gibco; Thermo Fisher Scientific, Inc.) with 5\% FBS, $0.5 \mu \mathrm{g} / \mathrm{ml}$ hydrocortisone (Sigma-Aldrich, Merck KGaA), $20 \mathrm{ng} / \mathrm{ml}$ epidermal growth factor (EGF; Sigma-Aldrich, Merck KGaA), $10 \mu \mathrm{g} / \mathrm{ml}$ insulin (Sigma-Aldrich, Merck KGaA) and antibiotics under a humidified atmosphere with $5 \% \mathrm{CO}_{2}$ and $95 \%$ air at $37^{\circ} \mathrm{C}$.

MDA-MB-231 and MCF-7 cells were serum-starved in DMEM for $24 \mathrm{~h}$, and MCF12A cells were serum-starved in DMEM/F12 for $18 \mathrm{~h}$ before treatment with inhibitors and/or EVs.

Patients. The patients enrolled between August 2014 and December 2018 consisted of 32 unrelated women who resided in Mexico City (median age, 57.7 years; age range, 38-80 years) from the First October Regional Hospital-ISSSTE (Mexico) with biopsy-diagnosed breast cancer at clinical stages II and III, and without receiving therapy. The control group consisted of 20 healthy women (median age, 42.7 years; age range, 16-86 years) who did not have any family history of breast cancer. All study participants provided signed informed consent, and the protocol was approved by The Committee of Research, Ethics and Biosafety of the First October Regional Hospital-ISSSTE, and was conducted in accordance with the Declaration of Helsinki. The pathological and clinical information of patients with breast cancer is shown in Table I.

Preparation of human plasma and isolation of EVs. In total, $4 \mathrm{ml}$ peripheral blood was collected into polypropylene tubes containing sodium citrate (Vacutainer System; BD Biosciences). Whole blood samples were centrifuged at $1,500 \mathrm{x} g$ for $15 \mathrm{~min}$ at $4^{\circ} \mathrm{C}$, and plasma samples were obtained. Isolation of EVs was performed as described previously (17). Then, one volume of $1 \mathrm{ml}$ plasma was centrifuged at $3,000 \mathrm{xg}$ for $30 \mathrm{~min}$ at $4^{\circ} \mathrm{C}$ to remove platelets. Plasma was obtained and centrifuged at $10,000 \mathrm{x}$ g for $30 \mathrm{~min}$ at $4^{\circ} \mathrm{C}$ to remove apoptotic bodies and platelet EVs, and supernatants were aliquoted and frozen at $-80^{\circ} \mathrm{C}$ until further analysis. Frozen samples were thawed on ice and centrifuged at $110,000 \times \mathrm{g}$ for $70 \mathrm{~min}$ at $4^{\circ} \mathrm{C}$ and pellets were reconstituted in PBS or DMEM (EV fractions). The absolute number of EVs was determined by flow cytometry using BD Trucount ${ }^{\mathrm{TM}}$ tubes (BD Biosciences) (18).

Transmission electron microscopy (TEM). TEM of EV fractions was performed as described previously (33). EV fractions were adsorbed for $5 \mathrm{~min}$ on carbon-coated copper grids with mesh formvar $(0.3 \%)$ at room temperature. The grids were stained for $30 \mathrm{sec}$ at room temperature with $2 \%$ uranyl acetate solution and excess fluid was removed. Grids were air-dried and analyzed using a JEM-1400 TEM (JEOL, Ltd.), operated at $80 \mathrm{kV}$ and coupled with a digital camera Veleta (Olympus SIS).

Nanoparticle tracking analysis (NTA). NTA was used to assess the size distribution of EV fractions. EV fractions were diluted in $10 \mathrm{ml}$ filtered PBS and analyzed with a NanoSight NS300 (Malvern Instruments, Ltd.), which was equipped with a $488 \mathrm{~nm}$ laser and a sCMOS camera. Then, three videos of each sample were captured at a duration of $60 \mathrm{sec}$ 
Table I. Patient characteristics.

Characteristics

Patients, $\mathrm{n}$

\section{Tumor type}

In situ ductal carcinoma

0

In situ lobular carcinoma

0

Invasive ductal carcinoma

32

Primary tumor size

T1

$\mathrm{T} 2$

$\mathrm{T} 3$

$\mathrm{T} 4$

1

20

8

3

Stage of breast cancer

$\begin{array}{lc}\text { In situ } & 0 \\ \text { I } & 0 \\ \text { II } & 20 \\ \text { III } & 12 \\ \text { IV } & 0\end{array}$

Lymph node status

Negative

Positive

Estrogen receptor status

Negative

Positive

Her2/Neu status

Negative

Positive

Progesterone receptor status

$\begin{array}{lc}\text { Negative } & 16 \\ \text { Positive } & 16 \\ \text { Age, years } & \\ \text { Median } & 57.7 \\ \text { Range } & 38-80\end{array}$

and data were analyzed with NTA v3.0 software (Malvern Instruments, Ltd.).

Stimulation of MDA-MB-231 cells with EVs. Cultures of MDA-MB-231 cells $\left(1.5 \times 10^{6}\right.$ cells/dish) were serum-starved for $24 \mathrm{~h}$, washed twice with PBS and then stimulated at different time periods with EV fractions $\left(20,000 \mathrm{EVs} / 1.5 \times 10^{6}\right.$ cells/experimental condition) from patients with breast cancer and healthy women. Scratch-wound assays were performed for $48 \mathrm{~h}$; invasion assays for $72 \mathrm{~h}$; proliferation assays for 48; and zymography assays for 3, 6, 9, 12 and $24 \mathrm{~h}$.

Western blotting. Cells and EVs were solubilized in $0.1 \mathrm{ml}$ of ice-cold RIPA buffer (50 mM HEPES pH 7.4, $150 \mathrm{mM}$ $\mathrm{NaCl}, 1 \mathrm{mM}$ EGT4, $1 \mathrm{mM}$ sodium orthovanadate, $100 \mathrm{mM}$ $\mathrm{NaF}, 10 \mathrm{mM}$ sodium pyrophosphate, $10 \%$ glycerol, $1 \%$ Triton $\mathrm{X}-100,1 \%$ sodium deoxycholate, $1.5 \mathrm{mM} \mathrm{MgCl}_{2}, 0.1 \%$ SDS and $1 \mathrm{mM}$ PMSF). Protein concentration of each sample was determined by using the Bradford protein assay (Bio-Rad
Laboratories, Inc.). Equal amounts of protein (30 $\mu \mathrm{g} /$ lane) were separated by SDS-PAGE on a $10 \%$ gel and proteins were transferred to nitrocellulose membranes. Nitrocellulose membranes were blocked for $2 \mathrm{~h}$ with $5 \%$ non-fat dried milk in PBS (pH 7.2/0.1\% Tween 20; wash buffer) at room temperature. The membranes were incubated with the following primary antibodies at $4^{\circ} \mathrm{C}$ overnight: Anti-Flotillin-2 (Flot-2) antibody (Ab; Mouse monoclonal; cat. no. 610383; 1:1,000; BD Biosciences), anti-CD9 Ab C-4 (Mouse monoclonal; cat. no. sc-13118; 1:300; Santa Cruz Biotechnology, Inc.), anti-FAK Ab D-1 (Mouse monoclonal; cat. no. sc-271126; 1:1,000; Santa Cruz Biotechnology, Inc.), anti-c-Src Ab 17AT28 (Mouse monoclonal; cat. no. sc-130124; 1:500; Santa Cruz Biotechnology, Inc.), anti-CD81 Ab EPR4244 (Rabbit monoclonal; cat. no. ab109201; 1:1,000; Abcam), anti-phosphorylated-specific Ab to Tyr-397 of FAK (anti-p-FAK Ab; Rabbit polyclonal; cat. no. 44-624G; IF 1:250; WB 1:1,000; Thermo Fisher Scientific, Inc.), anti-phosphorylated-specific Ab to Tyr-418 of Src (anti-p-Src Ab; rabbit polyclonal IgG; cat. no. AF2685; 1:1,000; R\&D Systems, Inc.), anti-vinculin Ab (Rabbit polyclonal; cat. no. V4139; IF 1:250; WB 1:500; Sigma-Aldrich; Merck KGaA) and anti-actin Ab (Mouse polyclonal; 1:1,000) was provided by Dr Manuel Hernandez (Cinvestav-IPN). Subsequently, membranes were washed three times with wash buffer and incubated with horseradish peroxidase-conjugated secondary Ab (cat. nos. G21040 and G21234; 1:5,000; Thermo Fisher Scientific, Inc.) for $2 \mathrm{~h}$ at room temperature, and washed again with wash buffer three times. ECL detection reagent (cat. no. sc-2048; Santa Cruz Biotechnology, Inc.) and images were used for visualization of immunoreactive bands. Bands were analyzed by using the ImageJ software v1.52e (National Institute of Health).

EV uptake assays using flow cytometry. EV uptake assays were performed as described previously $(34,35)$. EV fractions (20,000 EVs/condition) were stained via incubation for $30 \mathrm{~min}$ at $4^{\circ} \mathrm{C}$ with CellMask Orange dye solution $(2.5 \mu \mathrm{g} / \mathrm{ml})$. EV fractions were then washed with PBS, centrifuged at $110,000 \mathrm{x} g$ for $70 \mathrm{~min}$ at $4^{\circ} \mathrm{C}$ and reconstituted in $100 \mu \mathrm{l}$ DMEM. MDA-MB-231 cells $\left(1.5 \times 10^{6}\right.$ cells/condition) were incubated for $4 \mathrm{~h}$ at $37^{\circ} \mathrm{C}$ with stained EVs, and after incubation, cells were washed twice with PBS and fixed for $20 \mathrm{~min}$ at room temperature with a solution of $4 \%$ paraformaldehyde. Next, cells were incubated for $10 \mathrm{~min}$ at room temperature with a solution of trypsin $(0.1 \%)$, washed twice with PBS and re-suspended in PBS-1\% BSA (Santa Cruz Biotechnology, Inc.). Controls of inhibition of EVs uptake were included, and were obtained by treatment of EVs with $200 \mathrm{ng} / \mathrm{ml}$ Annexin V for $30 \mathrm{~min}$ at $4^{\circ} \mathrm{C}$, before staining of EVs with CellMask Orange dye solution for $30 \mathrm{~min}$ at $4^{\circ} \mathrm{C}$. Cells were analyzed using a BD FACSCalibur ${ }^{\mathrm{TM}}$ flow cytometer (BD Biosciences) and data analysis was performed with Summit v4.3 software (Beckman Coulter, Inc.).

EV uptake assays using confocal microscopy. MDA-MB-231 cells $\left(1.5 \times 10^{5}\right.$ cells/condition) were incubated with stained EVs (20,000/condition) for $4 \mathrm{~h}$ at $37^{\circ} \mathrm{C}$. After incubation, cells were washed twice with PBS, fixed for $20 \mathrm{~min}$ at room temperature with a solution of paraformaldehyde (4\%) and washed twice again with PBS. Next, cells were counterstained with Hoechst 
for $20 \mathrm{~min}$ at room temperature and mounted on glass slides using Vectashield. Preparations were analyzed by confocal microscopy (Model TCS SP2; Leica Microsystems, Inc.).

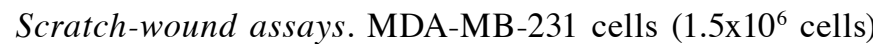
were cultured until they reached confluency and pretreated for $2 \mathrm{~h}$ at $37^{\circ} \mathrm{C}$ with $12 \mu \mathrm{M}$ mitomycin $\mathrm{C}$ to inhibit proliferation during the experiment. Cell cultures were scratched, washed with PBS and supplemented with serum-free DMEM with or without inhibitors and/or EV fractions (20,000 EVs/condition) at $37^{\circ} \mathrm{C}$. After treatment for $48 \mathrm{~h}$, the cultures were imaged using an inverted microscope coupled to a camera (FSX100; Olympus Corporation; magnification, x100). Images from $\geq 3$ fields per experimental condition were acquired and analyzed using ImageJ software v1.52e (National Institutes of Health). In total, one control of cell migration was included (5\% FBS).

Invasion assays. Inserts of 24-well plates (Costar; Corning, Inc.) were covered with $50 \mu 1$ Matrigel $(3 \mathrm{mg} / \mathrm{ml})$ and incubated at $37^{\circ} \mathrm{C}$ for $2 \mathrm{~h}$. Then, $1.2 \times 10^{5} \mathrm{MDA}-\mathrm{MB}-231$ cells in serum-free DMEM were plated on Matrigel of each insert in the upper chamber, and the lower chamber contained EV fractions $(20,000 \mathrm{EVs} /$ condition) in $600 \mu \mathrm{l} \mathrm{DMEM}$. The plates with the inserts were incubated at $37^{\circ} \mathrm{C}$ for $72 \mathrm{~h}$ under a humidified atmosphere with $5 \% \mathrm{CO}_{2}$ and $95 \%$ air. After incubation, cells and Matrigel on the upper surface of the membrane were removed, and cells on the lower surface of the membrane were washed with PBS followed by fixation for $12 \mathrm{~min}$ at room temperature with $4 \%$ paraformaldehyde. After fixation, invaded cells were imaged using an inverted microscope couple to a camera (FSX100, Olympus Corporation; magnification, x400). Quantification of invaded cells was calculated by staining membranes with $0.5 \%$ crystal violet for $15 \mathrm{~min}$ at room temperature and elution of the dye with $300 \mu 130 \%$ acetic acid. Absorbance of the collected solution was measured at $600 \mathrm{~nm}$. Cells treated with 5\% FBS were included as an invasion control.

Zymography. Conditioned media from TNBC MDA-MB-231 cells $\left(1.5 \times 10^{6}\right.$ cells $)$ treated with EV fractions $(20,000 \mathrm{EVs} /$ condition) at different time points $(3,6,9,12$ and $24 \mathrm{~h})$ at $37^{\circ} \mathrm{C}$ from women with breast cancer and healthy controls were concentrated using 5,000 Da Centricon ${ }^{\circledR}$ filters (EMD Millipore). An equal volume $(12 \mu \mathrm{l})$ of non-heated conditioned medium and sample buffer ( $2 \%$ sucrose, $2.5 \%$ SDS, $4 \mu \mathrm{g} / \mathrm{ml}$ phenol red) was mixed and the samples were loaded onto $8 \%$ acrylamide gels copolymerized with gelatin $(1 \mathrm{mg} / \mathrm{ml})$. Next, gels were rinsed three times for $30 \mathrm{~min}$ with Triton X-100 (2.5\%) and incubated in assay buffer $\left(50 \mathrm{mM}\right.$ Tris- $\left.\mathrm{HCl} \mathrm{pH} \mathrm{7.4,} 5 \mathrm{mM} \mathrm{CaCl}_{2}\right)$ for $48 \mathrm{~h}$ at $37^{\circ} \mathrm{C}$. After incubation, gels were stained for $1 \mathrm{~h}$ at room temperature with a solution of Coomassie Brilliant Blue G-250 (0.25\%) dissolved in acetic acid (10\%) and methanol (30\%). Proteolytic activity was identified as white zones on a blue background. Controls of MMP-2 and MMP-9 secretions were included, which were obtained by treatment of MDA-MB-231 cells with $400 \mathrm{mg} / \mathrm{dl}$ ethanol and $100 \mathrm{ng} / \mathrm{ml}$ phorbol-12,13-dibutyrate for $24 \mathrm{~h}$ at $37^{\circ} \mathrm{C}$, as treatment of cells with these compounds induces the expression and secretion of MMP-2 and MMP-9, respectively $(36,37)$.
Immunofluorescence confocal microscopy. MDA-MB-231 cells $\left(1.5 \times 10^{5}\right.$ cells) were grown on coverslips, washed with PBS, equilibrated in DMEM and treated with EV fractions (20,000 EVs/condition) for $30 \mathrm{~min}$ at $37^{\circ} \mathrm{C}$. Cells were fixed with paraformaldehyde (4\%) for $20 \mathrm{~min}$ at room temperature, permeabilized with $0.5 \%$ Triton X-100 and then blocked for $30 \mathrm{~min}$ at room temperature with FBS (10\%) dissolved in PBS. Next, cells were incubated overnight at $4^{\circ} \mathrm{C}$ with anti-p-FAK $\mathrm{Ab}$ (1:250) followed by FITC-labeled anti-mouse secondary $\mathrm{Ab}$ (cat. no. 115-095-003; Jackson ImmunoResearch, Inc) for $2 \mathrm{~h}$ at $4^{\circ} \mathrm{C}$. Staining of focal contacts was performed by incubation of cells with anti-vinculin $\mathrm{Ab}$ for $12 \mathrm{~h}$ at $4^{\circ} \mathrm{C}$, while staining of cells for fibrillar actin was performed by incubation for $2 \mathrm{~h}$ at $4^{\circ} \mathrm{C}$ with TRITC-conjugated phalloidin (cat. no. R415; Thermo Fisher Scientific, Inc.) Cells then were analyzed by confocal microscopy (Model TCS SP2; Leica Microsystems, Inc.).

Cell proliferation assay. MDA-MB-231 cells (30,000 cells per well) were treated for $48 \mathrm{~h}$ at $37^{\circ} \mathrm{C}$ with $\mathrm{EV}$ fractions (20,000 EVs/condition). Next, $10 \mu \mathrm{l}$ WST-1 reagent (cat. no. ab65473; Abcam) was added to the cells in each well and microplates were incubated at $37^{\circ} \mathrm{C}$ for $2 \mathrm{~h}$. The absorbance of each well was measured at $450 \mathrm{~nm}$, and one control for proliferation was included, which was prepared by treatment of cells with $5 \% \mathrm{FBS}$ for $48 \mathrm{~h}$ at $37^{\circ} \mathrm{C}$.

Statistical analysis. Data are presented as the mean \pm SD of $\geq 3$ independent experiments. Data were analyzed by one-way ANOVA followed by Tukey's post hoc test for $\geq 3$ groups, while Student's t-test was used to analyze groups of two. $\mathrm{P}<0.05$ was considered to indicate a statically significant difference.

\section{Results}

EVs from plasma of patients with breast cancer induce the migration of MDA-MB-231 cells. The present study characterized EV fractions using NTA, TEM and western blotting against Flot-2, CD9 and CD81, which are molecular markers associated with EVs (7). NTA and TEM results identified a population of spherical vesicles with sizes between 30-300 nm in healthy women, while women with breast cancer had vesicles between 50-600 nm (Fig. 1A and B). Moreover, NTA showed that the number of EVs was significantly higher in women with breast cancer $\left(1.542 \times 10^{11} \mathrm{EVs} / \mathrm{ml}\right)$ than in healthy women $\left(2.14 \times 10^{10} \mathrm{EVs} / \mathrm{ml}\right)$. Western blotting results demonstrated the presence of Flot-2, CD9 and CD81 protein expression in EV fractions from healthy women (Ctrl EVs) and $\mathrm{EV}$ fractions from women with breast cancer (BC EVs; Fig. 1C).

Next, whether BC EVs induced migration in TNBC MDA-MB-231 cells was investigated. Cell migration assays were performed using scratch-wound assays with MDA-MB-231 cells treated with EVs from 22 patients with breast cancer and from 15 healthy women. The results indicated that $\mathrm{BC}$ EVs induced increased migration compared with Ctrl EVs in MDA-MB-231 cells (Fig. 1D). In addition, the association between the migration induced by BC EVs in MDA-MB-231 cells and the expression levels of estrogen, progesterone and Her2/neu receptors in the mammary tumors of the women from where the plasma EVs were obtained was analyzed. It was found that the migration induced by $\mathrm{BC}$ 

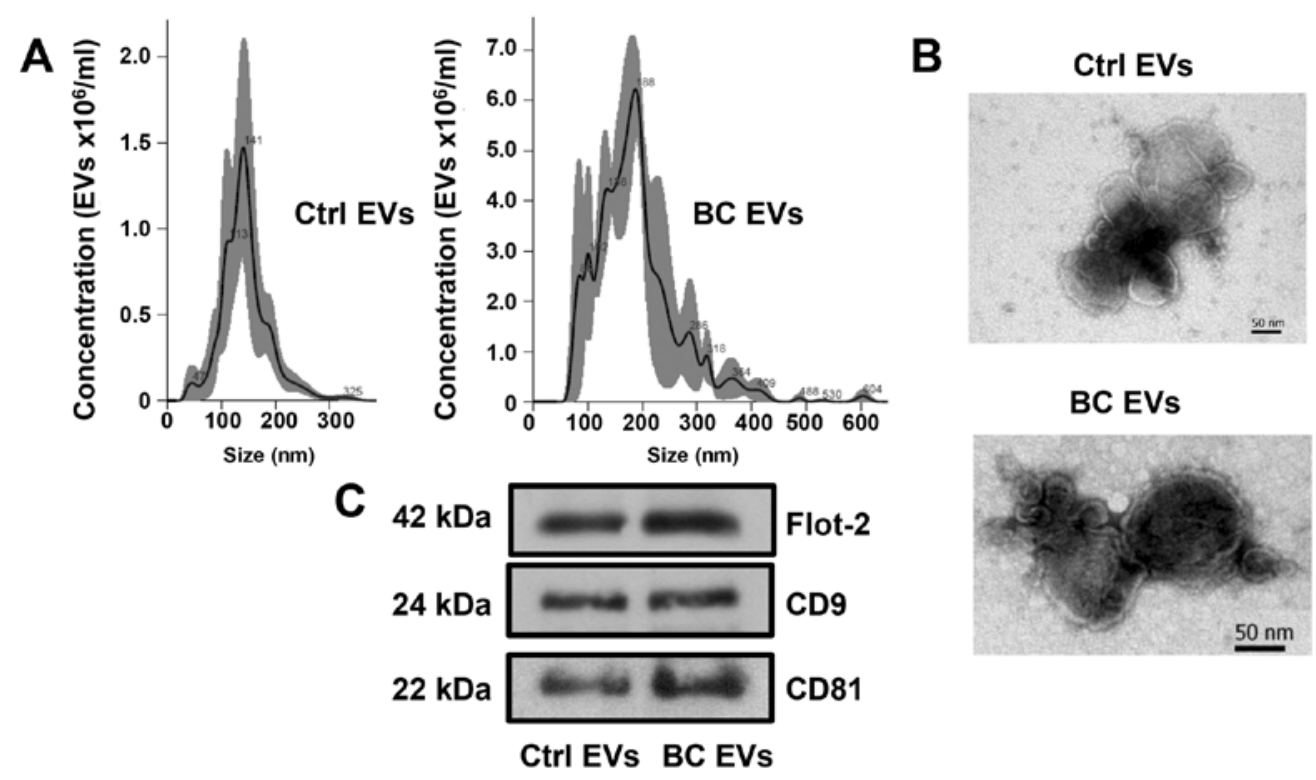

BC EVs

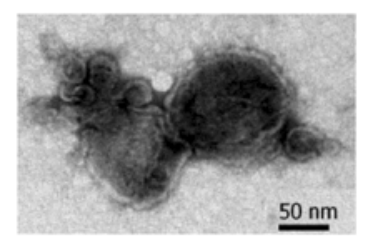

D

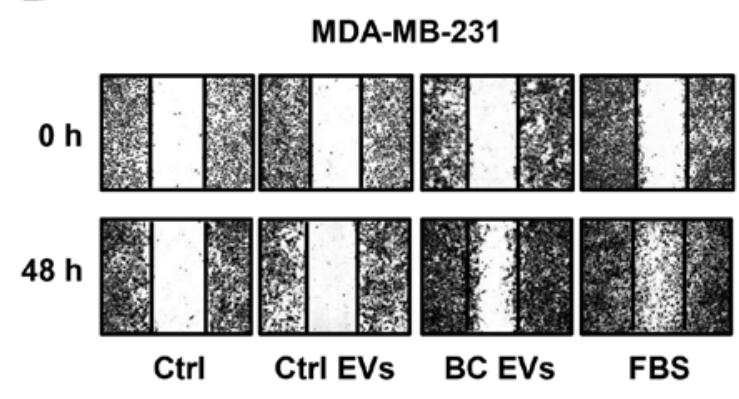

E
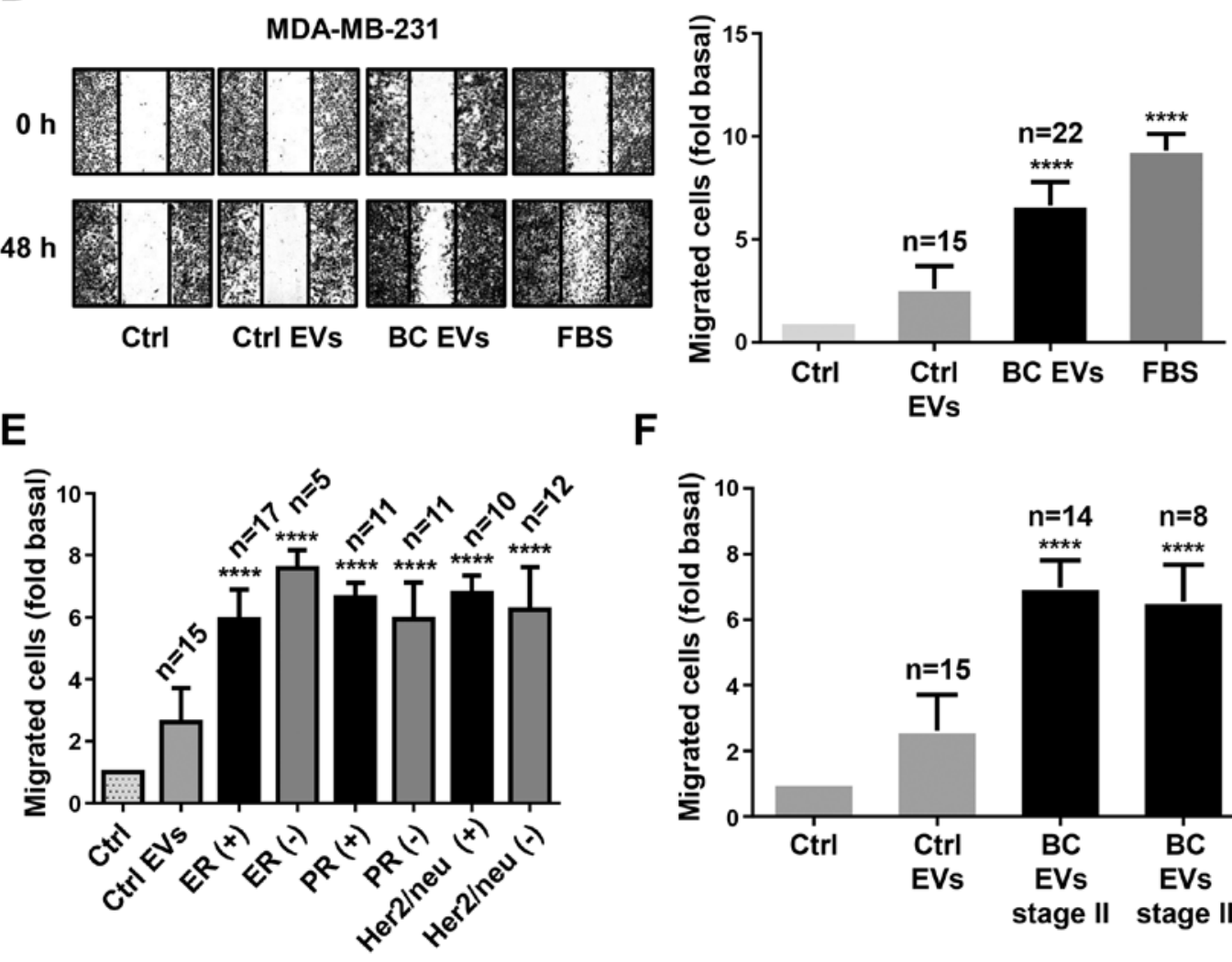

$\mathbf{F}$

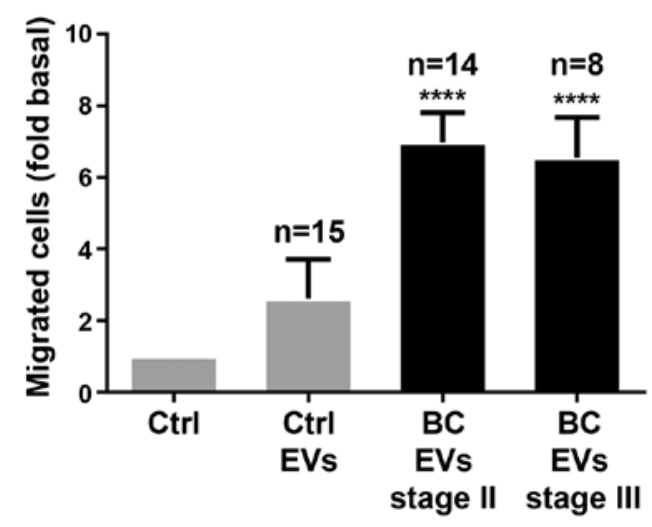

Figure 1. EVs from plasma of patients with breast cancer enhance migration in MDA-MB-231 cells. (A) Ctrl EVs and BC EVs were analyzed by nanoparticle tracking analysis. The calculated size distribution of particles was depicted as the mean (black line) with standard errors (gray shaded area). (B) Ctrl EVs and BC EVs were visualized by transmission electron microscopy. (C) Ctrl EVs and BC EVs were analyzed by western blotting with anti-Flot-2 Ab, anti-CD9 Ab and anti-CD81 Ab. Images are representative of three independent experiments. (D) Cultures of MDA-MB-231 cells were scratch-wounded and treated for 48 $\mathrm{h}$ with Ctrl EVs and BC EVs; one control of FBS was included. (E) Analysis of migration induced by BC EVs in relation to expression of ER, PR and Her2/neu overexpression. (F) Analysis of migration induced by BC EVs in relation to clinical stage of patients. Magnification, 100x. Data are presented as the mean \pm SD, and indicate the fold of migration above Ctrl. ${ }^{* * * * *} \mathrm{P}<0.0001$ vs. Ctrl. Ctrl, control; Ctrl EVs, EV fractions obtained from healthy women; BC EVs, EV fractions obtained from women with breast cancer; Ab, antibody; ER, estrogen receptor; PR, progesterone receptor; EVs, extracellular vesicles; Flot-2, flotillin-2.

EVs was not related with the expression levels of estrogen, progesterone and Her2/neu receptors in the tumors of women with breast cancer (Figs. 1E and S1A). Furthermore, migration of MDA-MB-231 cells induced by BC EVs was not related with the stages II and III of the women with breast cancer (Figs. 1F and S1B).
To further examine these findings, whether BC EVs induced migration and/or invasion was determined in another breast cancer cell line (MCF-7) and mammary non-tumorigenic epithelial cells (MCF12A). The results showed that treatment with BC EVs did not induce migration in MCF-7 cells, and it did not induce migration and invasion in MCF12A cells (Fig. 2A-C). 
A

MCF-7

$0 \mathrm{~h}$

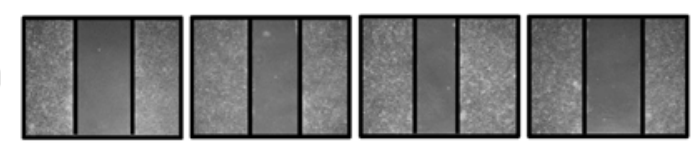

$48 \mathrm{~h}$

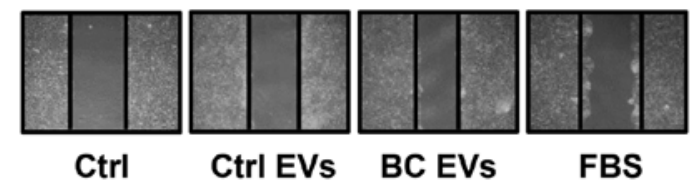

B
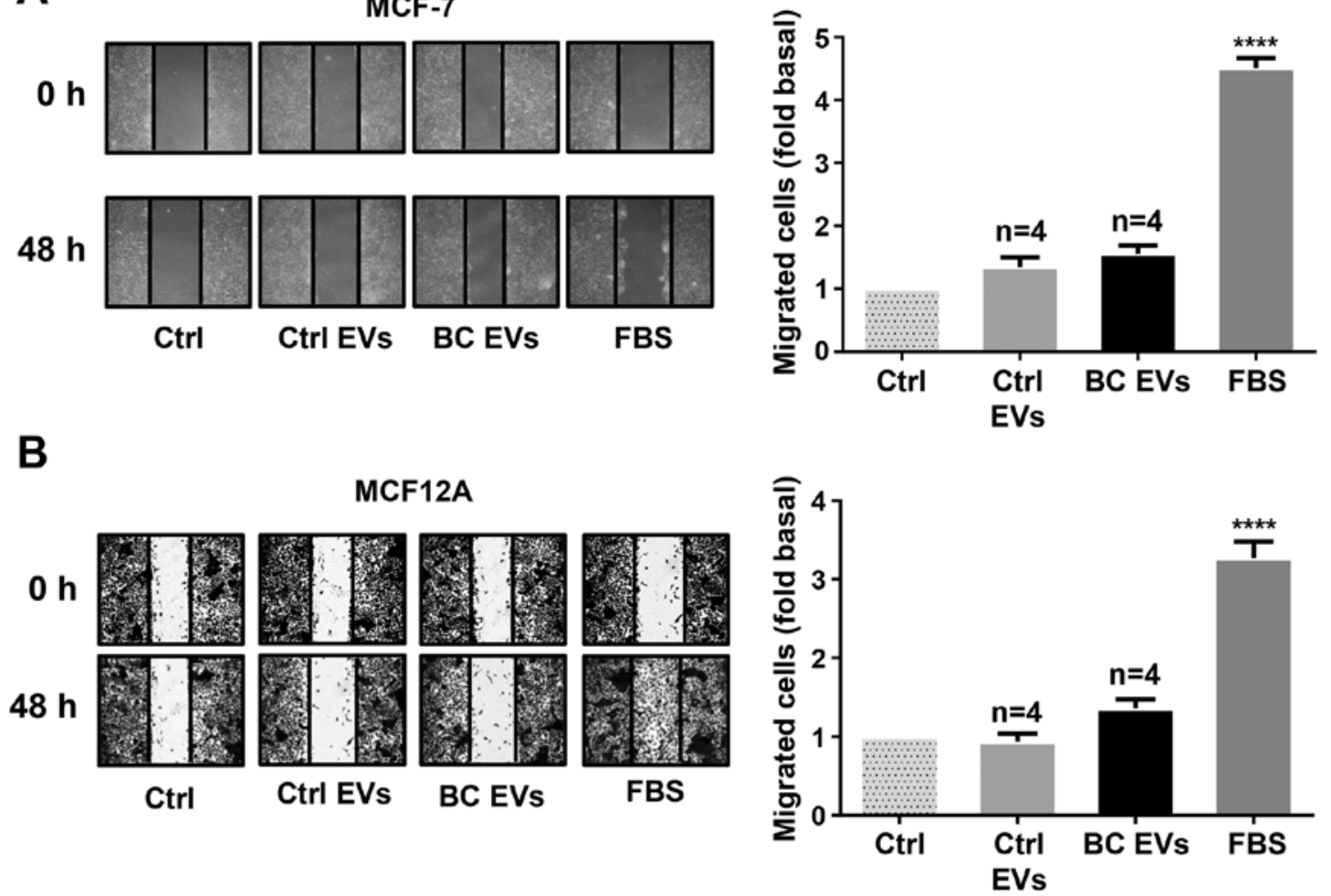

C

MCF12A

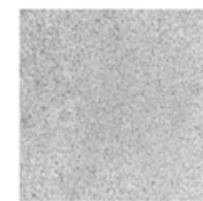

Ctrl

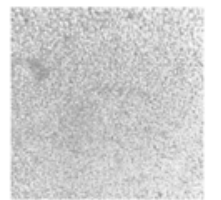

BC EVs

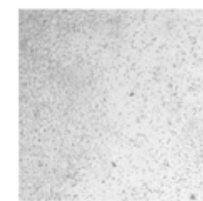

Ctrl EVs

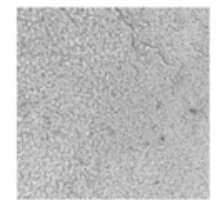

FBS

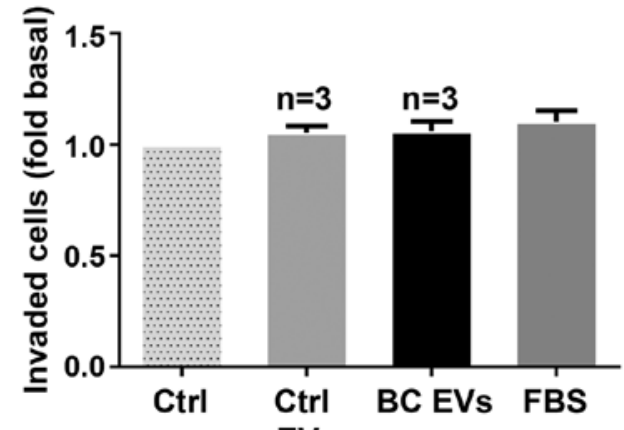

EVs

Figure 2. EVs from plasma of patients with breast cancer do not enhance migration and invasion in MCF-7 and MCF12A cells. (A and B) Cultures of MCF-7 and MCF12A cells were scratch-wounded and treated for $48 \mathrm{~h}$ with Ctrl EVs and BC EVs. Magnification, x100. (C) Invasion assays were performed with MCF12A cells treated with Ctrl EVs and BC EVs; one control of FBS was included. Magnification, $\mathrm{x} 400$. Data are presented as the mean \pm SD, and indicate the fold of migration or invasion above Ctrl. ${ }^{* * * *} \mathrm{P}<0.0001$ vs. Ctrl. Ctrl, control; Ctrl EVs, EV fractions obtained from healthy women; BC EVs, EV fractions obtained from women with breast cancer; EVs, extracellular vesicles.

EVs from healthy women and patients with breast cancer are taken up by $M D A-M B-231$ cells. It was studied whether Ctrl EVs and BC EVs were taken up by MDA-MB-231 cells. Ctrl EVs and BC EVs were labeled with CellMask orange dye, MDA-MB-231 cells were incubated with unstained EVs and stained EVs, and the fluorescence intensity was analyzed by flow cytometry. It was identified that fluorescence intensity was higher in MDA-MB-231 cells treated with stained Ctrl EVs and stained BC EVs compared with MDA-MB-231 cells treated with unstained EVs (Figs. 3A and B and S2). In addition, the comparison of fluorescence intensity was not significantly different between the value obtained from MDA-MB-231 cells treated with stained $\mathrm{BC}$ EVs and the value obtained from MDA-MB-231 cells treated with stained Ctrl EVs (Fig. 3C).
EVs express PS on their surface, and Annexin V has a strong and specify affinity for PS (38). Controls of uptake inhibition were included, and were obtained by treatment of EVs with $200 \mathrm{ng} / \mathrm{ml}$ Annexin V, before staining of EVs with CellMask Orange dye. The results indicated that treatment of stained Ctrl EVs with Annexin V inhibited the increase of fluorescence intensity induced by stained Ctrl EVs (Fig. 3A). However, treatment of BC EVs with Annexin V did not inhibit the increased fluorescence intensity induced by stained $\mathrm{BC}$ EVs (Fig. 3B).

To further examine whether EVs are taken up by breast cancer cells, MDA-MB-231 cells treated with stained Ctrl EVs, stained BC EVs and unstained BC EVs were analyzed by confocal microscopy. It was found that MDA-MB-231 cells 


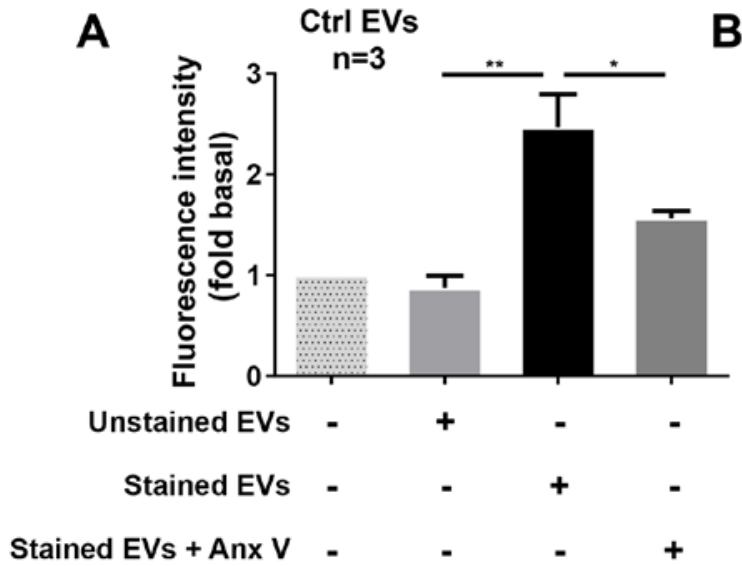

B

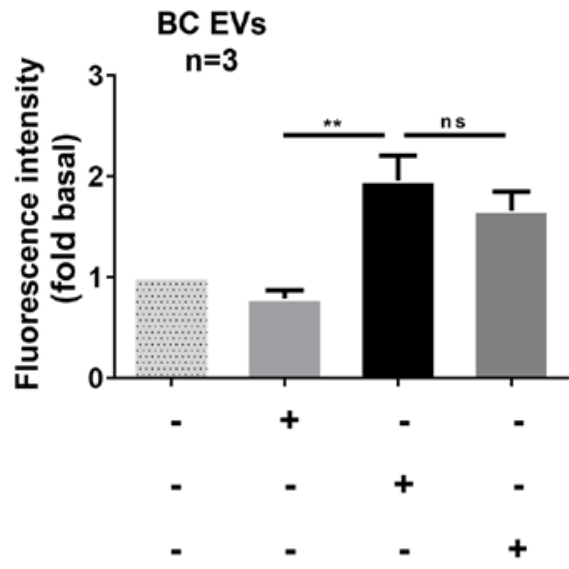

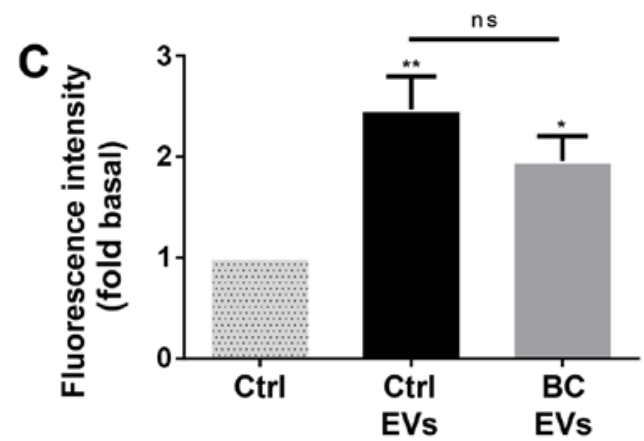

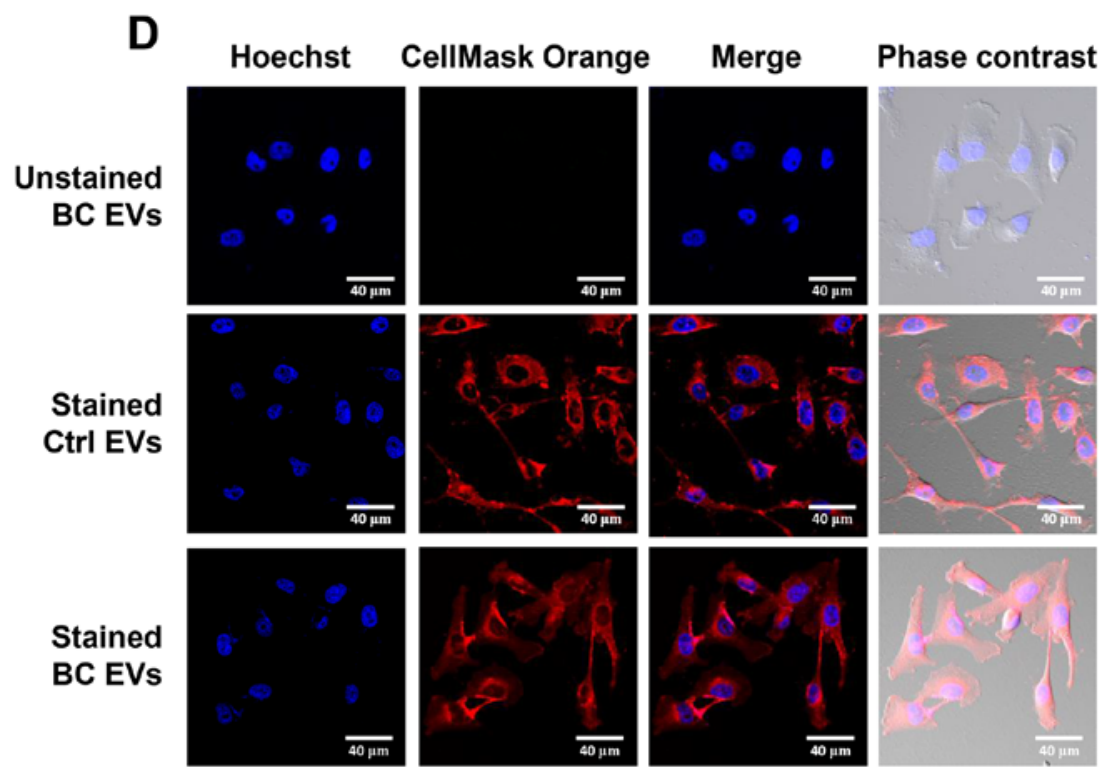

Figure 3. EVs from plasma of healthy and breast cancer groups are taken up by MDA-MB-231 cells. (A and B) Flow cytometry analysis of MDA-MB-231 cells incubated with unstained or stained Ctrl EVs and unstained or stained BC EVs. Controls of cells without treatment with EVs and uptake inhibition (Annexin V) were included. (C) Comparison of stained EVs uptake between MDA-MB-231 cells treated with stained BC EVs and stained Ctrl EVs. (D) Confocal microscopy analysis of MDA-MB-231 cells incubated with unstained BC EVs, stained Ctrl EVs, stained BC EVs and nucleus stained with Hoechst dye. Scale bar, $40 \mu \mathrm{m}$. Data are presented as the mean fluorescence intensities $\pm \mathrm{SD}$, and indicate the fold of fluorescence intensity above Ctrl and Ctrl EVs. ${ }^{*} \mathrm{P}<0.05,{ }^{* *} \mathrm{P}<0.01$ vs. Ctrl or as indicated. ns, not significant; Ctrl, control; EVs, extracellular vesicles; Ctrl EVs, EV fractions obtained from healthy women; BC EVs, EV fractions obtained from women with breast cancer.

treated with stained BC EVs and stained Ctrl EVs showed a red staining, while cells treated with unstained BC EVs did not show any color (Fig. 3D).

EVs from patients with breast cancer induce secretion of gelatinases. It was determined whether treatment of MDA-MB-231 cells with BC EVs induced gelatinase secretion. MDA-MB-231 cells were stimulated for 3, 6, 9, 12 and $24 \mathrm{~h}$ with EVs from three patients with breast cancer, and stimulated for $24 \mathrm{~h}$ with EVs from three healthy women. Conditioned media were obtained, concentrated and analyzed by gelatin zymography. It was identified that stimulation of MDA-MB-231 cells with BC EVs induced increased secretion of MMP-2 and MMP-9 at 12 and $24 \mathrm{~h}$ of treatment (Fig. 4A). 
A

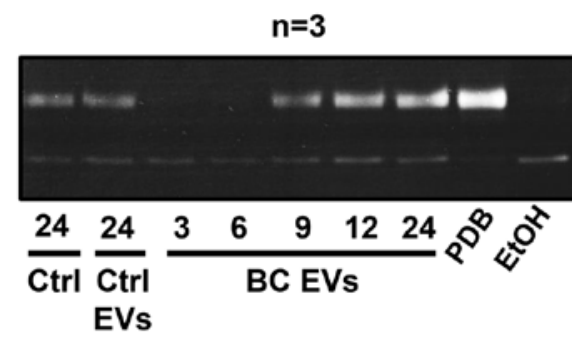

MMP-9

MMP-2

Time (h)
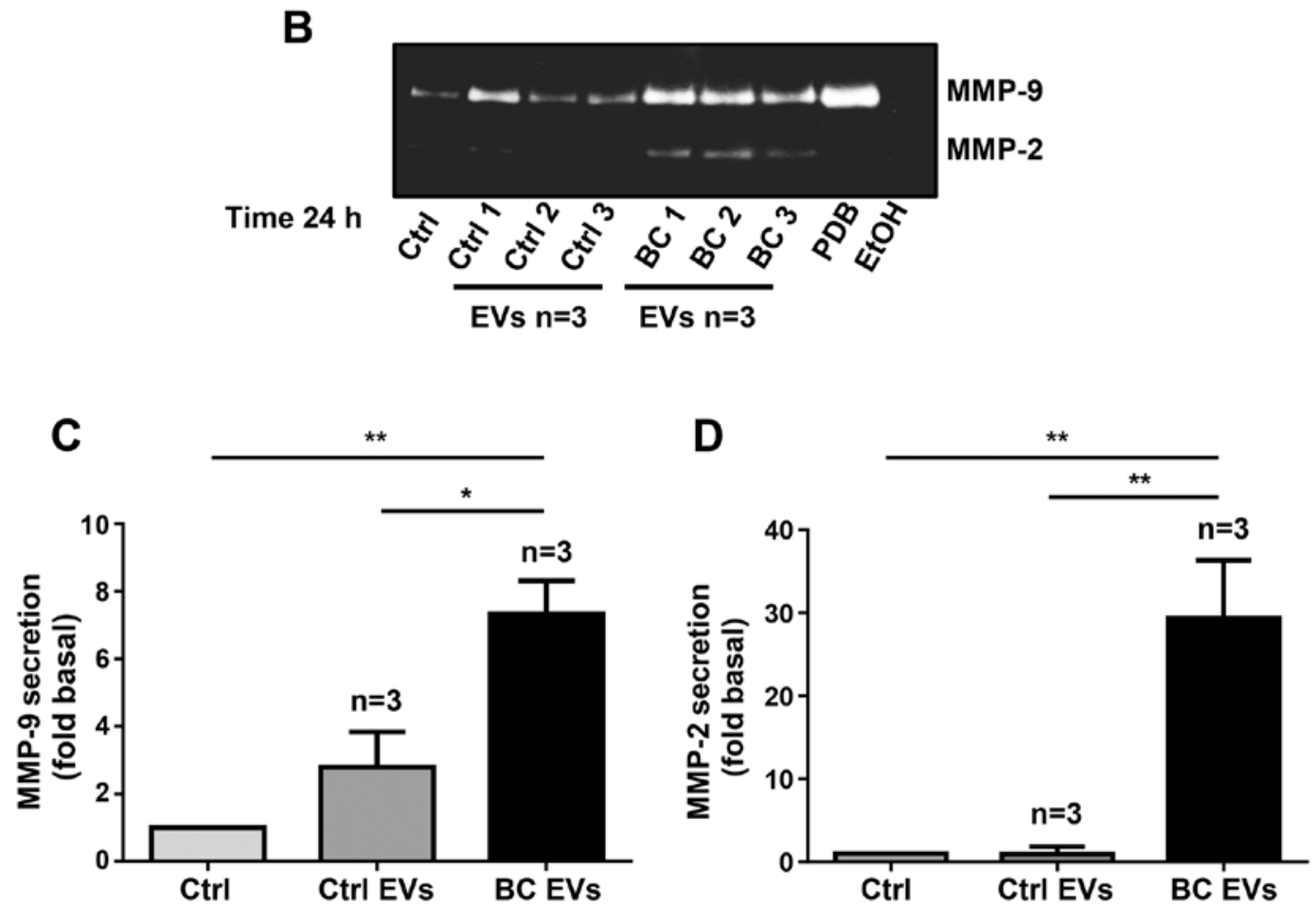

Figure 4. EVs isolated from patients with breast cancer mediate secretion of gelatinases. (A) MDA-MB-231 cells were incubated for various times with EVs from three healthy women and EVs from three patients with breast cancer, and conditioned media were collected. (B) MDA-MB-231 cells were incubated for $24 \mathrm{~h}$ with EVs from three healthy women and three patients with breast cancer. Gelatinase secretion was analyzed by gelatin-substrate gels, and positive controls of MMP-2 (EtOH) and MMP-9 (PDB) secretions were included. (C and D) Densitometric analysis of MMP-9 and MMP-2 secretion. Data are presented as the mean \pm SD, and are expressed as fold of MMP-2 or MMP-9 secretion above Ctrl and Ctrl EVs. ${ }^{*} \mathrm{P}<0.05,{ }^{* *} \mathrm{P}<0.01$ as indicated. Ctrl, control; EVs, extracellular vesicles; Ctrl EVs, EV fractions obtained from healthy women; BC EVs, EV fractions obtained from women with breast cancer; MMP, matrix metalloproteinase; EtOH, ethanol; PBD, phorbol-12,13-dibutyrate.

Since treatment of MDA-MB-231 cells with BC EVs for $24 \mathrm{~h}$ induced MMP-2 and MMP-9 secretion, MDA-MB-231 cells were treated for $24 \mathrm{~h}$ with EVs from three patients with breast cancer and EVs from three healthy women, and supernatants were analyzed by gelatin zymography. The results indicated that treatment of MDA-MB-231 cells with Ctrl EVs induced a small increase in MMP-9 secretion, but stimulation with BC EVs induced a significant increase in both MMP-9 and MMP-2 secretion (Fig. 4B-D).

EVs from patients with breast cancer induce Src activation. In order to determine whether treatment of MDA-MB-231 cells with BC EVs induced Src activation, which is initiated by its phosphorylation at Tyr-418 (p-Src), MDA-MB-231 cells were treated for $20 \mathrm{~min}$ with three Ctrl EV samples and three BC EV samples, and cell lysates were analyzed by western blotting with anti-p-Src Ab. It was identified that treatment of MDA-MB-231 cells with Ctrl EVs induced a small level of phosphorylation of Src at Tyr-418, while treat- ment with BC EVs induced a strong phosphorylation of Src at Tyr-418 (Fig. 5A).

Next, whether Ctrl EVs and BC EVs contain p-Src and Src kinase was determined by western blotting with $\mathrm{p}-\mathrm{Src} \mathrm{Ab}$ and $\mathrm{Src} \mathrm{Ab}$. The results showed that Ctrl EVs contained a low amount of p-Src, while BC EVs contained a significantly larger amount of p-Src (Fig. 5B). However, it was demonstrated that Ctrl EVs and BC EVs contained a similar amount of Src kinase (Fig. 5B).

EVs from patients with breast cancer induce FAK activation via Src activity. The present study determined whether BC EVs induced FAK activation, which is induced by its phosphorylation at Tyr-397 (p-FAK). Lysates of MDA-MB-231 cells treated for 20 min with three Ctrl EV samples and three BC EV samples were analyzed by western blotting with anti-p-FAK Ab. It was identified that treatment with Ctrl EVs induced low levels of phosphorylation of FAK at Tyr-397, whereas treatment with BC EVs induced a significantly higher level of phosphorylation of FAK at Tyr-397 (Fig. 6A). 
A
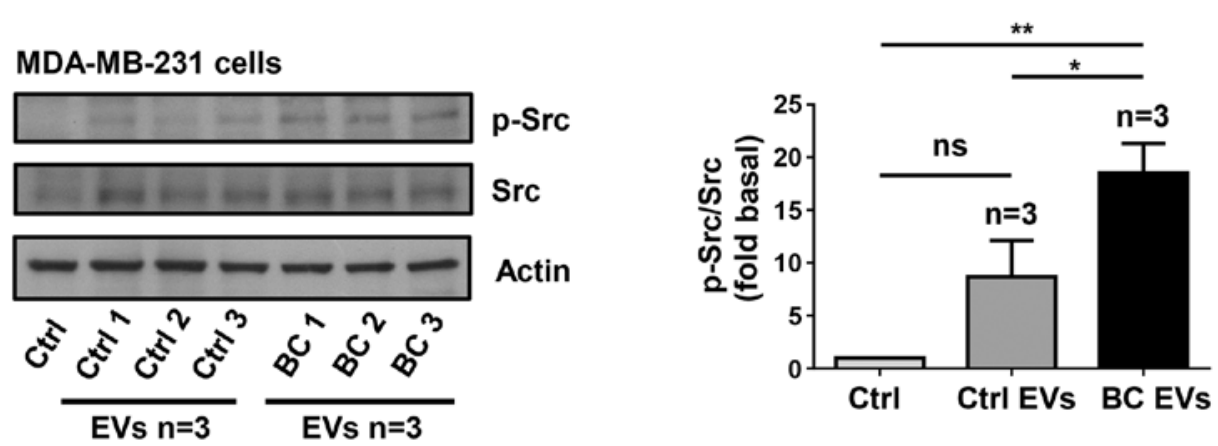

B
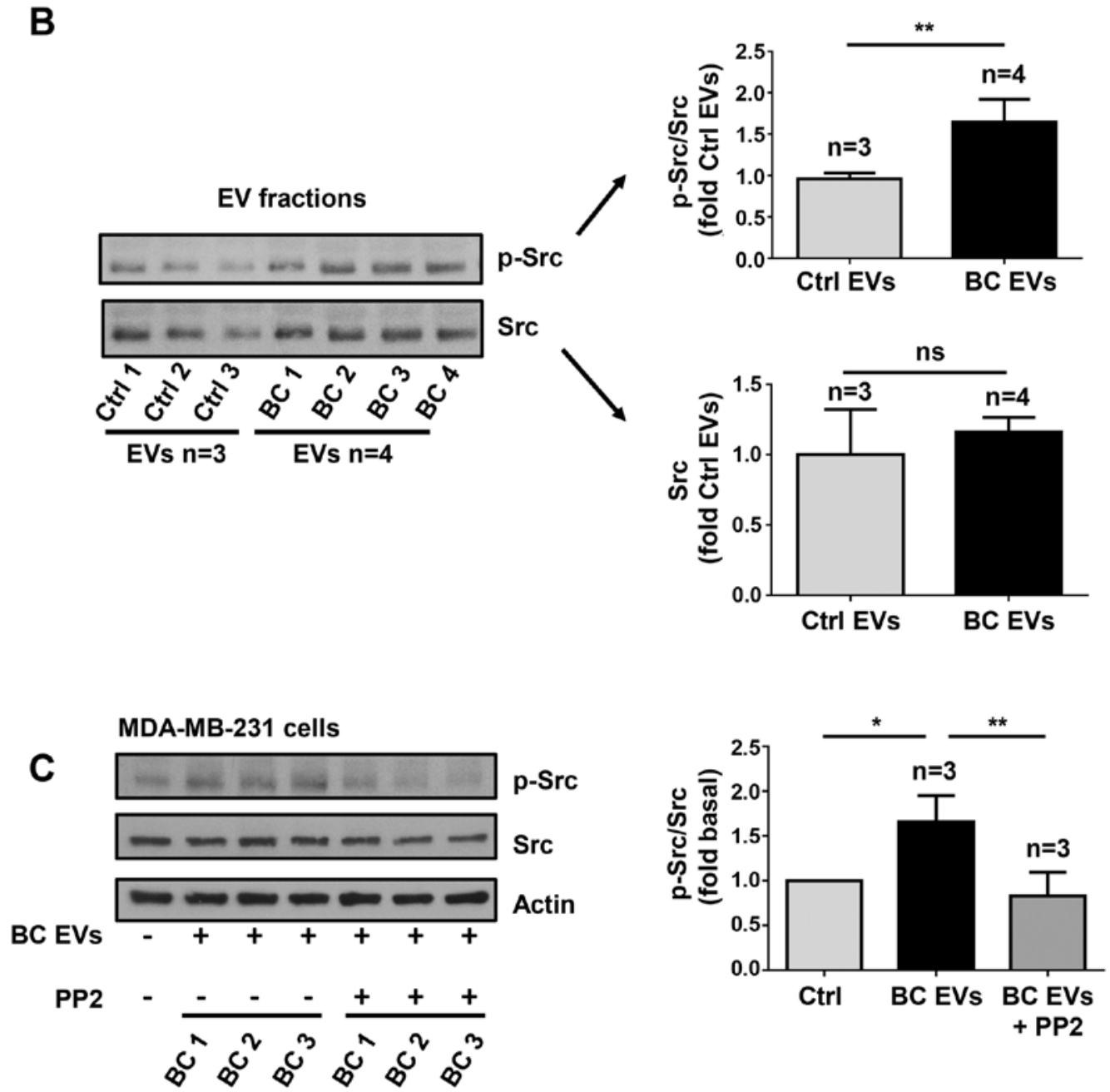

Figure 5. EVs isolated from patients with breast cancer induce Src activation. (A) Lysates from MDA-MB-231 cells treated for 20 min with three Ctrl EVs and three BC EVs were analyzed by western blotting with anti-p-Src Ab. Membranes were further analyzed with anti-Src Ab and anti-actin Ab as loading controls. (B) Three Ctrl EVs and four BC EVs were analyzed by western blotting with anti-p-Src Ab and anti-Src Ab. (C) Lysates from MDA-MB-231 cells untreated and treated for $1 \mathrm{~h}$ with $10 \mu \mathrm{M}$ PP2 and stimulated for $20 \mathrm{~min}$ with three BC EVs were analyzed by western blotting with anti-p-Src Ab. Membranes were further analyzed with anti-Src Ab and anti-actin Ab as loading controls. Data are presented as the mean \pm SD, and indicate the fold of p-Src or Src above Ctrl or Ctrl EVs. ${ }^{*} \mathrm{P}<0.05,{ }^{* *} \mathrm{P}<0.01$ vs. Ctrl and Ctrl EVs. ns, not significant; Ctrl, control; Ab, antibody; EVs, extracellular vesicles; Ctrl EVs, EV fractions obtained from healthy women; BC EVs, EV fractions obtained from women with breast cancer; p-, phosphorylated.

Since Src is able to induce maximal FAK activation mediated by G-protein-coupled receptors (GPCRs) and tyrosine kinase receptors (27), the role of Src in FAK activation was investigated. The role of Src was examined using PP2, which is a specific inhibitor of Src family members (39). To determine whether PP2 inhibited the activity of Src, MDA-MB-231 cells were untreated and treated for $1 \mathrm{~h}$ with $10 \mu \mathrm{M}$ PP2 and then treated for $20 \mathrm{~min}$ with three BC EVs, and lysed. Cell lysates were analyzed by western blotting with anti-p-Src Ab, and it was found that PP2 inhibited the increase of p-Src induced by BC EVs (Fig. 5C). Next, MDA-MB-231 cells were untreated and treated for $1 \mathrm{~h}$ with $10 \mu \mathrm{M}$ PP2 and stimulated for 20 min with BC EVs. It was identified that treatment with $\mathrm{BC}$ EVs induced an increase of p-FAK via a Src-dependent pathway in MDA-MB-231 cells (Fig. 6B). 
A
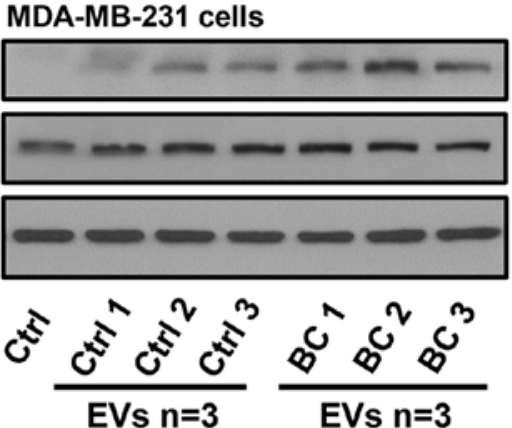

p-FAK

FAK

Actin

B

MDA-MB-231 cells

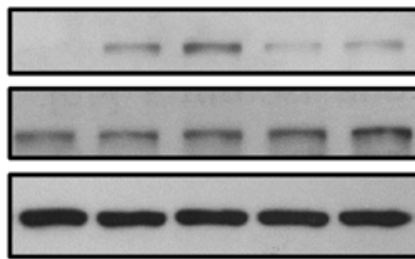

p-FAK

FAK

Actin
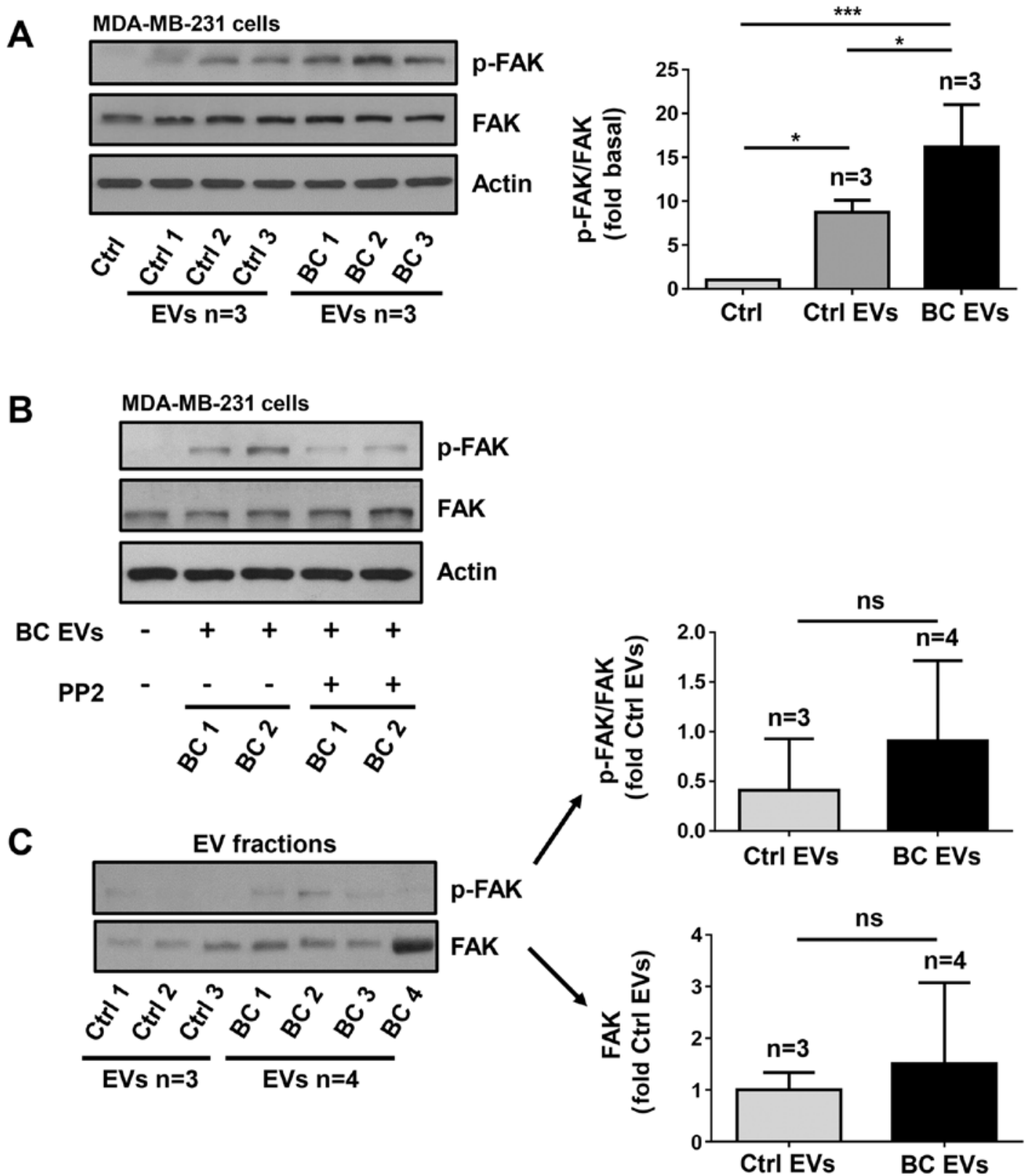

Figure 6. EVs isolated from patients with breast cancer induce FAK activation via a Src-dependent pathway. (A) Lysates from MDA-MB-231 cells treated for 20 min with three Ctrl EVs and three BC EVs were analyzed by western blotting with anti-p-FAK Ab. Membranes were further analyzed by western blotting with anti-FAK Ab and anti-actin Ab as loading controls. (B) MDA-MB-231 cells were untreated and treated for $1 \mathrm{~h}$ with $10 \mu \mathrm{M}$ PP2 and stimulated for 20 min with two BC EVs and lysed. Cell lysates were analyzed by western blotting with anti-p-FAK Ab. Membranes were analyzed further with anti-FAK Ab and anti-actin Ab as loading controls. (C) Three Ctrl EVs and four BC EVs were analyzed by western blotting with anti-p-FAK Ab and anti-FAK Ab. Data are presented as the mean $\pm \mathrm{SD}$, and indicate the fold of p-FAK or FAK above Ctrl and Ctrl EVs. ${ }^{*} \mathrm{P}<0.05$, ${ }^{* * *} \mathrm{P}<0.001$ vs. Ctrl and Ctrl EVs. ns, not significant; Ctrl, control; Ab, antibody; EVs, extracellular vesicles; Ctrl EVs, EV fractions obtained from healthy women; BC EVs, EV fractions obtained from women with breast cancer; p-, phosphorylated; FAK, focal adhesion kinase.

The present study also assessed whether p-FAK and FAK were localized in EV fractions, and three Ctrl EVs and four $\mathrm{BC}$ EVs were analyzed by western blotting with p-FAK Ab and FAK Ab. The results showed that Ctrl EVs and BC EVs expressed variable levels of p-FAK and FAK, and there was no significant difference in p-FAK and FAK expression levels between Ctrl EVs and BC EVs (Fig. 6C)

EVs from patients with breast cancer induce redistribution of $p$-FAK and focal adhesions assembly. It was examined whether BC EVs induced a redistribution of p-FAK, as well as the assembly of focal adhesions and the role of Src in the assembly of focal adhesions. MDA-MB-231 cells cultured on coverslips were untreated or treated for $1 \mathrm{~h}$ with $10 \mu \mathrm{M} \mathrm{PP} 2$ and stimulated with Ctrl EVs and BC EVs. The redistribution of p-FAK was analyzed by immunofluorescence with anti-p-FAK Ab. Moreover, the number of focal adhesions was analyzed by immunofluorescence with anti-vinculin $\mathrm{Ab}$, as vinculin is a cytoplasmic actin binding protein enriched in focal adhesions (40). It was demonstrated that $\mathrm{BC}$ EVs induced the redistribution of p-FAK at the edges of cells, and increased the number of focal adhesions (Fig. 7A and B). Furthermore, focal adhesion assembly induced by BC EVs was 
A

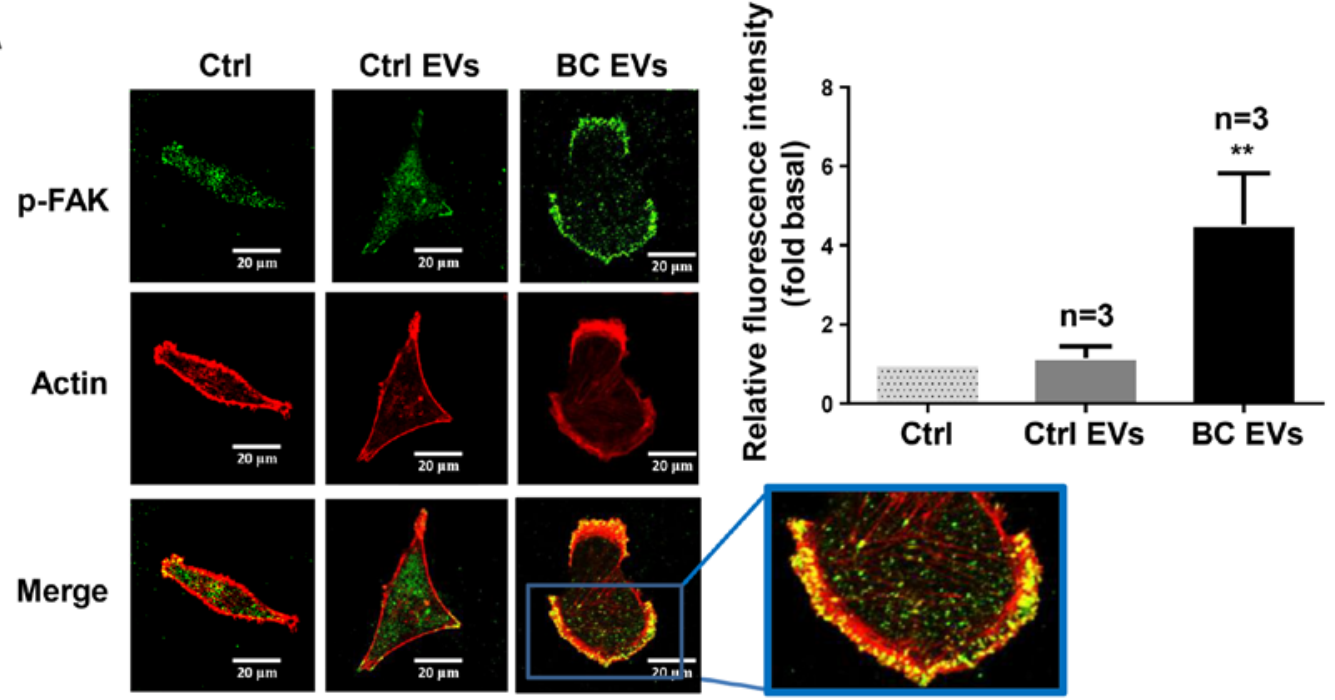

B

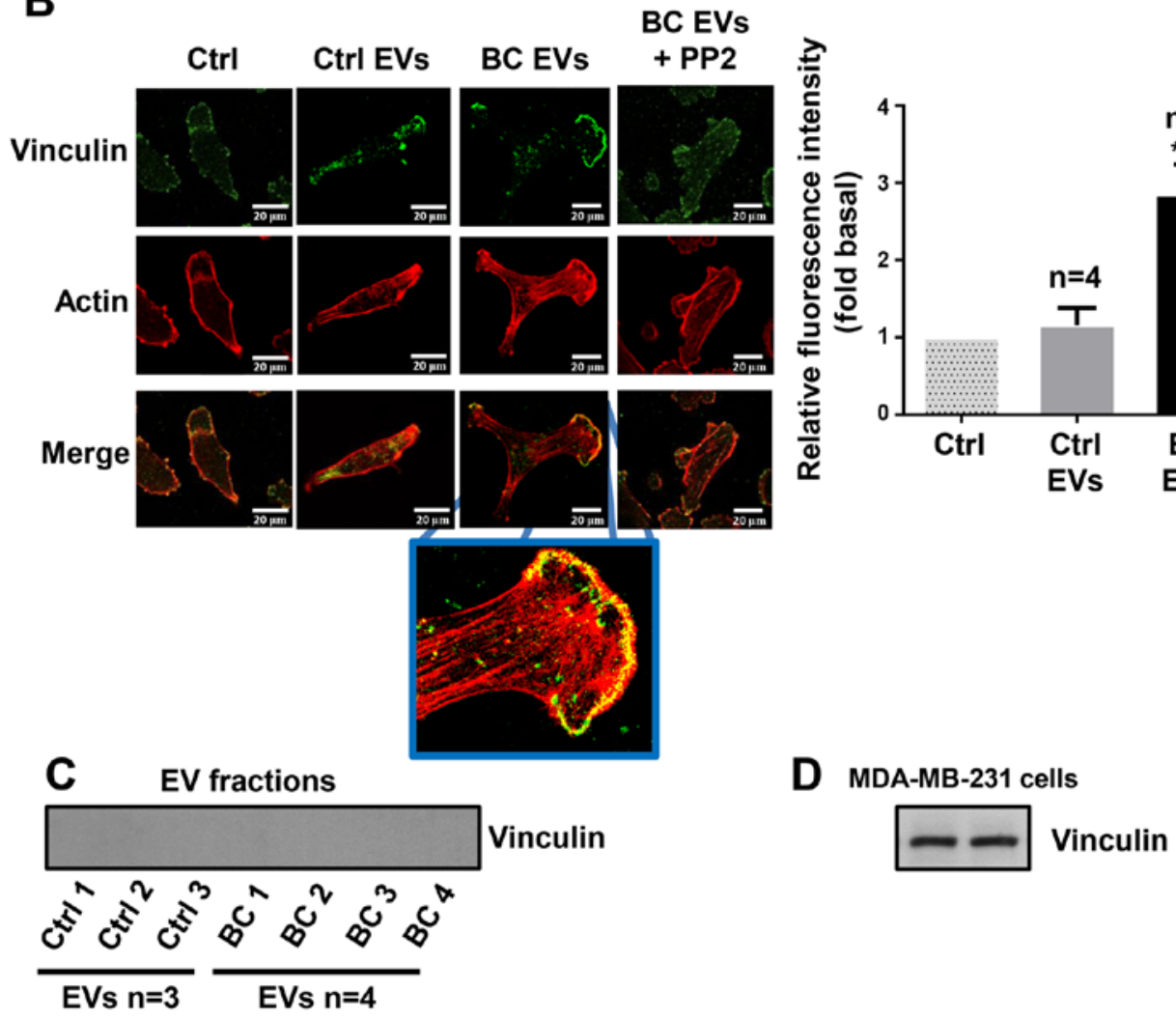

Figure 7. EVs from patients with breast cancer induce redistribution of p-FAK and focal adhesions assembly. (A and B) MDA-MB-231 cells cultured on coverslips were treated for $1 \mathrm{~h}$ with or without $10 \mu \mathrm{M}$ of PP2, and stimulated for 30 min with Ctrl EVs and BC EVs. Cells were incubated with Abs against p-FAK, vinculin and tetramethylrhodamine-conjugated phalloidin, and were analyzed by confocal microscopy. (C) Analysis of vinculin in Ctrl EVs and BC EVs by western blotting. (D) Whole cell lysates of MDA-MB-231 cell were included as a control of vinculin expression. Data are presented as the mean \pm SD of fluorescent intensities of p-FAK and vinculin, and are expressed as fold above Ctrl. ${ }^{* *} \mathrm{P}<0.01,{ }^{* * * * *} \mathrm{P}<0.0001 \mathrm{vs}$. Ctrl. ns, not significant; Ctrl, control; Ab, antibody; EVs, extracellular vesicles; Ctrl EVs, EV fractions obtained from healthy women; BC EVs, EV fractions obtained from women with breast cancer; p-, phosphorylated; FAK, focal adhesion kinase.

dependent on Src activity (Fig. 7B). In addition, the present study determined whether vinculin was localized in EV fractions, and three Ctrl EVs and four BC EVs were analyzed by western blotting with anti-vinculin $\mathrm{Ab}$; the results indicated that $\mathrm{Ctrl} \mathrm{EVs}$ and BC EVs did not express vinculin (Fig. 7C). One control of vinculin expression was included (Fig. 7D).
Role of Src in migration and invasion mediated by EVs from patients with breast cancer. The role of Src in migration was examined using PP2 and its inactive analog (PP3) (39). Cultures of MDA-MB-231 cells were treated for $1 \mathrm{~h}$ with $10 \mu \mathrm{M}$ PP2 or $10 \mu \mathrm{M}$ PP3, scratch-wounded and stimulated with Ctrl EVs and BC EVs. It was demonstrated that migration induced 
A
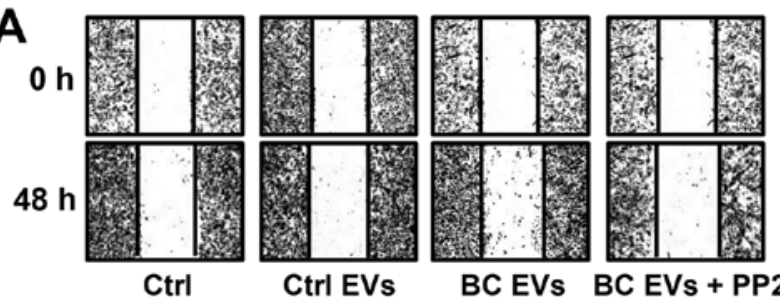

$\mathbf{O h}$

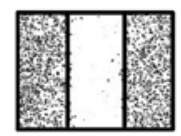

$48 \mathrm{~h}$

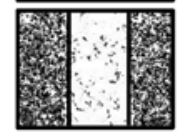

BC EVs + PP3

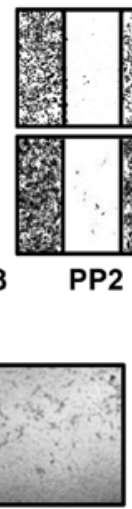

C

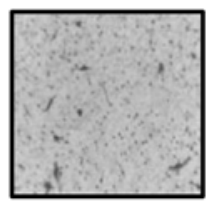

Ctrl
Ctrl

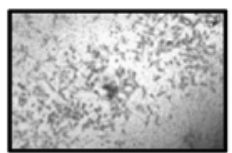

BC EVs
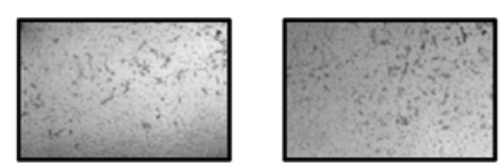

Ctrl EVs

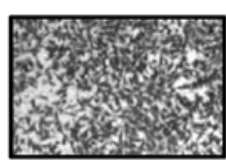

FBS
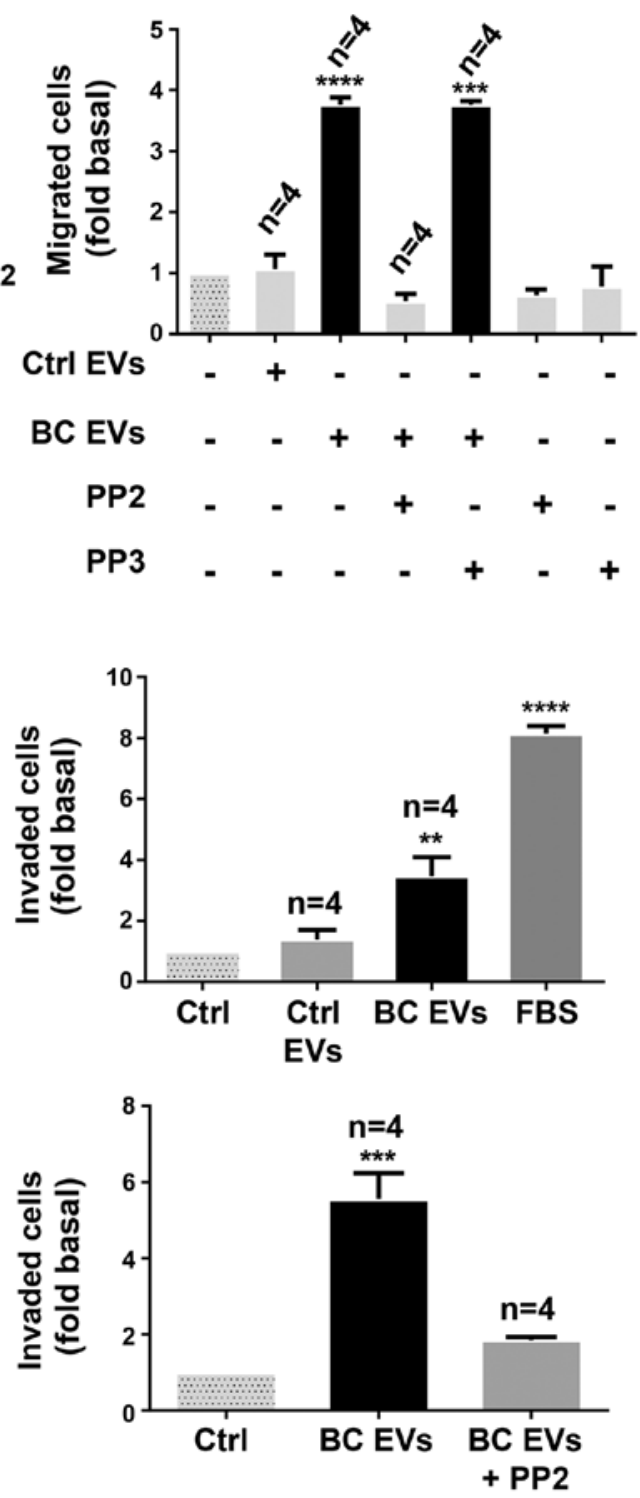

D

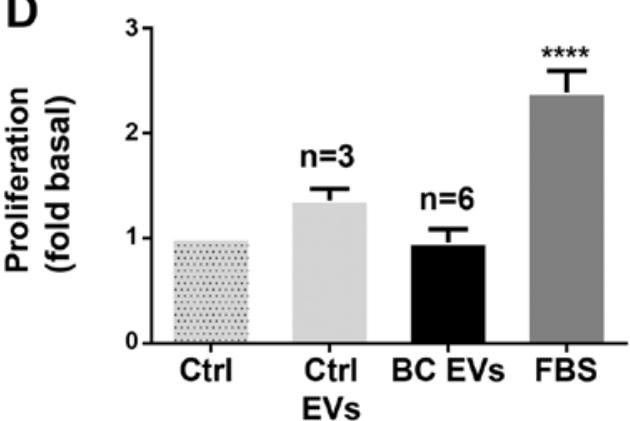

Figure 8. EVs from patients with breast cancer induce migration and invasion via a Src-dependent pathway. (A) Migration assays of MDA-MB-231 cells treated for $1 \mathrm{~h}$ with or without $10 \mu \mathrm{M}$ PP2 or $10 \mu \mathrm{M} \mathrm{PP} 3$, and stimulated for $48 \mathrm{~h}$ with Ctrl EVs and BC EVs. Magnification, x100. (B and C) Invasion assays of MDA-MB-231 cells treated with or without $10 \mu \mathrm{M}$ PP2 and stimulated for $48 \mathrm{~h}$ with Ctrl EVs and BC EVs. Magnification, x400. (D) Proliferation assay of MDA-MB-231 cells incubated with Ctrl EVs and BC EVs. FBS was included as the control. Data are presented as the mean \pm SD, and are expressed as fold of migration, invasion or proliferation above Ctrl. ${ }^{* *} \mathrm{P}<0.01,{ }^{* * *} \mathrm{P}<0.001,{ }^{* * * * *} \mathrm{P}<0.0001$ vs. Ctrl. Ctrl, control; EVs, extracellular vesicles; Ctrl EVs, EV fractions obtained from healthy women; BC EVs, EV fractions obtained from women with breast cancer.

by BC EVs was dependent on Src activity in MDA-MB-231 cells (Fig. 8A).

Next, it was studied whether BC EVs induced invasion, and the role of Src was assessed using invasion assays with MDA-MB-231 cells treated with Ctrl EVs and BC EVs. It was identified that BC EVs induced invasion of MDA-MB-231 cells
(Fig. 8B). Moreover, invasion assays performed in the presence of PP2 demonstrated that invasion required Src activity (Fig. 8C).

In addition, whether $\mathrm{BC}$ EVs induce proliferation in MDA-MB-231 cells was examined, and proliferation assay results found that $\mathrm{BC}$ EVs and Ctrl EVs did not induce proliferation in MDA-MB-231 cells (Fig. 8D). 


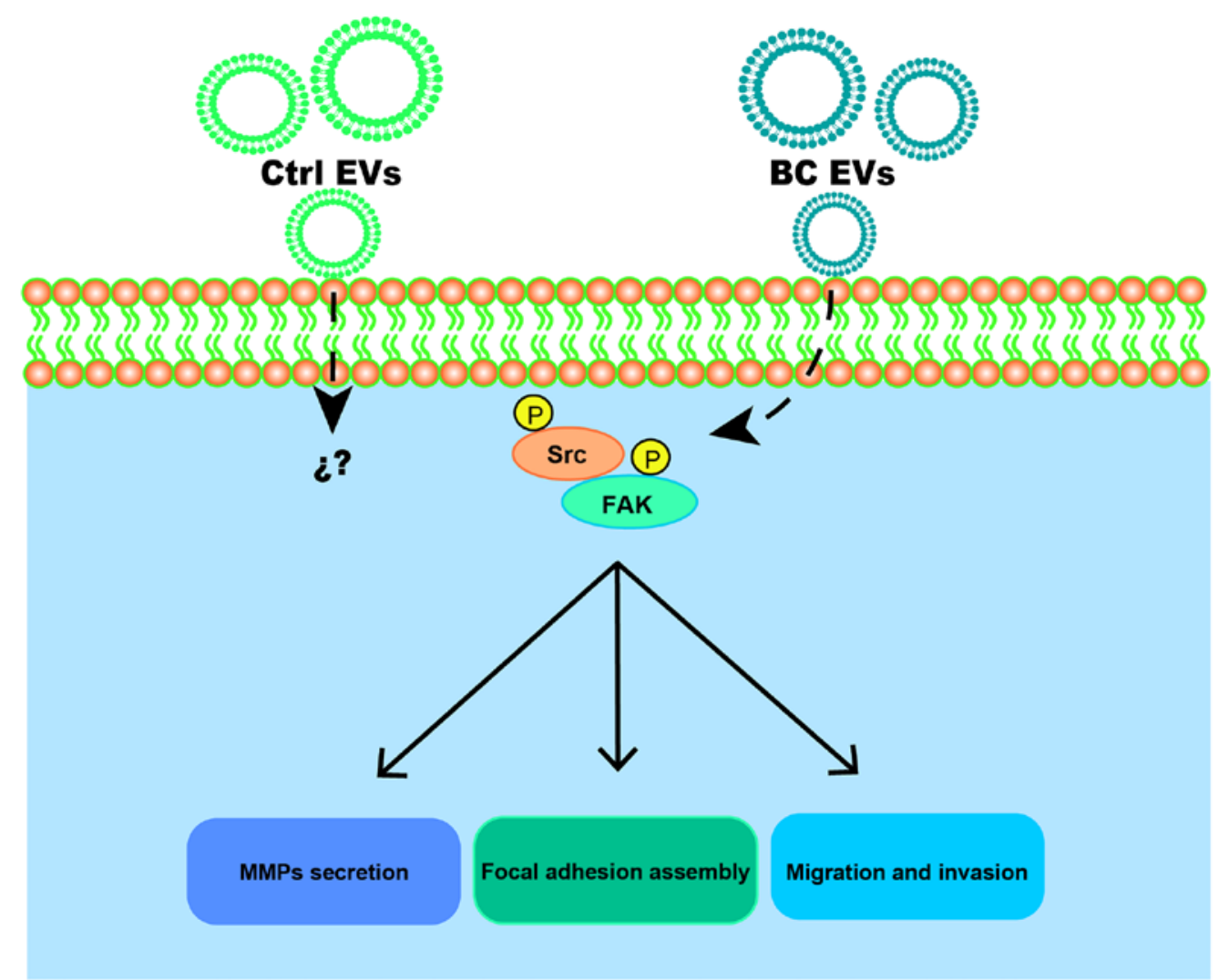

Figure 9. Proposed roles of EVs obtained from patients with breast cancer in the migration and invasion of MDA-MB-231 breast cancer cells. EVs, extracellular vesicles; Ctrl EVs, EV fractions obtained from healthy women; BC EVs, EV fractions obtained from women with breast cancer; p, phosphorylated; FAK, focal adhesion kinase; MMP, matrix metalloproteinase.

\section{Discussion}

EVs are comprised of exosomes and microvesicles, which constitute a variety of vesicles between 30-1,000 nm (7). The present study isolated EVs from plasma samples as described previously by Baran et al (17), as this method was reported to isolate EVs via the depletion of EVs from platelets. In plasma, EVs from platelets constitute $\sim 80 \%$ of total EVs $(17,41)$. The present results demonstrated that isolated EV fractions are comprised of vesicles with sizes between 30-300 $\mathrm{nm}$ in healthy women, while women with breast cancer showed EVs from 50-600 nm. Furthermore, both Ctrl EVs and BC EVs expressed molecular markers associated with EVs. Therefore, it was speculated that isolated EV fractions from plasma samples corresponded to exosomes and microvesicles, which are not contaminated with cell debris and apoptotic bodies, and were free of platelet-derived EVs. Therefore, it was proposed that cell processes studied may be mediated by exosomes and/or microvesicles. The contribution of microvesicles and exosomes to the cell processes analyzed remains to be investigated.

Moreover, the present results demonstrated that the number of EVs in plasma is higher in women with breast cancer than in healthy women; however, the number of EVs in the present study were found to be higher than the number of EVs reported in a previous study (18). A different number of EVs was found in the present study because the number of EVs was determined using NTA, while in the previous study the number of EVs was determined by flow cytometry. NTA has a higher sensitivity for determining the number of EVs than flow cytometry. However, both studies demonstrated that the number of EVs is higher in women with breast cancer than in healthy women.

Cancer metastasis consists of several sequential steps, including detachment of cells, migration, invasion to surrounding tissues, intravasation, survival in circulation, extravasation and colonization. Moreover, invasion of cancer cells to other tissues involves cell migration as single cells (mesenchymal type) or epithelial sheets (42). EVs are implicated in intercellular communication in the tumor microenvironment, as they mediate crosstalk between cancer and stromal cells (43). In addition, EVs support cancer development, adaptation to hypoxic conditions, deprivation of nutrients, escape of apoptosis, immune evasion and cancer progression (43-45). Furthermore, exosomes released from cancer-associated fibroblasts (CAFs) induce the formation of protrusions and motility in MDA-MB-231 cells, while mesenchymal stem cells secrete exosomes that promote motility and invasiveness in breast cancer cells $(46,47)$. It has been shown that Hs578T cells and their more invasive variant Hs578T(i) $)_{8}$ secrete EVs that promote proliferation, migration and invasion in breast cancer cells (48). The present results showed that EVs from women with breast cancer stages II and III induced cell migration and this was dependent on Src activity in MDA-MB-231 cells. However, EVs from healthy women did not induce migration in MDA-MB-231 cells. Moreover, migration induced by EVs from patients with breast cancer was independent of the expression levels of estrogen, progesterone and Her-2/neu receptors in the tumors of patients. In contrast, it was identified that BC EVs did not induce migration in MCF-7 cells, and did not induce 
migration and invasion in MCF12A mammary epithelial cells. However, in contrast to the present results, it has been previously reported that exosomes from healthy women stimulate migration and invasion in MDA-MB-231 cells (49). Thus, it was speculated that BC EVs consist of subpopulations of exosomes and microvesicles secreted from cancer cells (tumor) and stromal cells, such as tumor-associated macrophages, mesenchymal stem cells and CAFs. Therefore, BC EVs have a larger capacity for the induction of cell migration and invasion compared with Ctrl EVs in MDA-MB-231 cells. Thus, this may be the reason for the lack of the migration and invasion mediated by stimulation with EVs from healthy women.

Furthermore, it was speculated that only BC EVs contain molecules that induce the activation of specific signal transduction pathways, including Src activation, which mediate a variety of cell processes, including migration in breast cancer cells. It was identified that $\mathrm{BC}$ EVs do not induce migration and/or invasion in MCF12A mammary epithelial cells and MCF-7 breast cancer cells, which express progesterone and estrogen receptors. Furthermore, the present results suggested that EVs from women with breast cancer stages II and III can induce migration in breast cancer cells that do not express these receptors, and that this was a specific process in TNBC cells. Moreover, it was speculated that EVs in patients with breast cancer play an important role in cancer progression, as they are able to induce migration and invasion. In line with the present results, it has been reported that treatment of HMLE human mammary epithelial cells with exosomes from MDA-MB-231 cells transfected with microRNA-1246 increases its ability for drug resistance, growth and invasion (50). In addition, K562 myeloid leukemia cells release exosomes that promote angiogenesis via Src activation, while exosomes from C4-2B, PC3 and DUI45 prostate cancer cells contain Src, insulin-like growth factor 1 (IGF-1) receptor and FAK, which are molecules involved in cell migration and invasion $(51,52)$.

Tumor cells communicate with surrounding cells, including CAFs, endothelial cells and mesenchymal cells, via the secretion and uptake of EVs, which mediate biological processes, such as migration, angiogenesis and invasion, and can also modulate the tumor microenvironment and metastasis $(34,43,53)$. The present results indicated that MDA-MB-231 cells are able to take up BC EVs and Ctrl EVs, however only BC EVs induce migration. Thus, BC EVs may have cargo molecules that promote activation of specific signal transduction pathways, which increases migration and invasion in breast cancer cells.

EVs express PS on their membrane surface, which mediates the fusion of EVs with target cells. Therefore, treatment of EVs with Annexin V inhibits the fusion of EVs with target cells, as Annexin V binds to PS $(43,54,55)$. In the present study, it was identified that treatment of Ctrl EVs with Annexin V inhibited the increase of fluorescence intensity mediated by Ctrl EVs. However, treatment of BC EVs with Annexin V did not inhibit the increased fluorescence intensity mediated by BC EVs. Thus, it was speculated that BC EVs do not express, or express very low levels, of PS on their membrane surface. It has been reported that EV fractions obtained from females with type I diabetes and controls without disease contain both EVs expressing PS and EVs without expression of PS (56), which is consistent with the present results. Moreover, the percentage of
PS in EVs from patients is $31 \%$, while the percentage of PS in controls without disease is $44 \%$ (56).

Src family kinases mediate a variety of cellular processes, such as cell cycle progression, proliferation, survival and migration (57). Furthermore, it has been reported that breast cancer tumors and cell lines have an increase in Src activity (58). In addition, linoleic acid induces FAK and Src activation, and cell migration via a Src-dependent pathway in MDA-MB-231 cells (28). The present results demonstrated that stimulation with BC EVs induced a stronger activation of FAK and Src compared with treatment with Ctrl EVs, and also increased the number of focal adhesions in MDA-MB-231 cells. As FAK and Src activation and focal adhesion assembly mediate migration and invasion, it was speculated that BC EVs induced the activation of signal transduction pathways, including the activation of FAK and Src, which mediated migration and invasion in MDA-MB-231 cells. In line with the present results, mouse embryonic fibroblasts expressing onco-Dbl release microvesicles containing FAK and stimulation of fibroblasts with these vesicles promotes proliferation, which is independent of anchorage and survival in fibroblasts (59).

A variety of phosphoproteins, including Src, have been revealed in EVs from human plasma (60). Moreover, EVs from plasma of women with breast cancer contain FAK and EGFR kinases, and the level of these kinases are increased in specific stages of breast cancer in comparison with the control group (18). Furthermore, the present results indicated that Ctrl EVs and BC EVs contained similar expression levels of p-FAK, FAK and Src, but BC EVs contained larger amounts of p-Src compared with Ctrl EVs. Thus, it was demonstrated, that BC EVs induced FAK and Src activation; however, the contribution of p-FAK, FAK, p-Src and Src expressed in EVs to the activation of these kinases in the target MDA-MB-231 cells requires further investigation.

A catalytic reciprocal activation model of FAK and Src has been previously reported, where Src associates with FAK and phosphorylates FAK at Tyr-576 and Tyr-577, which induces maximal kinase activity of FAK $(32,61,62)$. In addition, it has been revealed that maximal kinase activity of FAK promotes intermolecular phosphorylation between FAK molecules at Tyr-397, which induces signal amplification $(32,61,62)$. In line with this model, the present results demonstrated that $\mathrm{BC}$ EVs induced activation of FAK, which was dependent on Src kinase activity. Linoleic acid, oleic acid and arachidonic acid induce activation of FAK via GPCRs and a mechanism of reciprocal catalytic activation of FAK (28,63-65). Therefore, it was speculated that EVs mediated activation of FAK and Src, as well as migration and invasion via activation of receptors.

Tumors release EVs that play a pivotal role in the invasion and metastasis processes, EVs from patients with breast cancer are associated with metastasis and relapse $(14,43)$. In the present study, it was identified that EVs from patients with breast cancer induced migration and invasion via Src activity in MDA-MB-231 cells. Moreover, in line with the present results, it has been shown that exosomes from patients with TNBC induce invasion in SKBR3 cells (48). In addition, it was found that treatment of non-tumorigenic mammary epithelial cells MCF12A with BC EVs does not induce migration. It is proposed that $\mathrm{BC}$ EVs may mediate progression processes in breast cancer via the transfer of molecules and activation 
of signal transduction pathways. Supporting this hypothesis, different tumors release EVs with a variety of integrin expression patterns, which are able to determine organ specific metastasis $(14,66)$. Moreover, EVs expressing $\alpha 6 \beta 4$ and $\alpha 6 \beta 1$ integrins are associated with lung metastasis, while EVs expressing $\alpha v \beta 5$ are associated with liver metastasis $(14,66)$.

ECM degradation is required for tumor growth and metastasis (67). In addition, EVs contain proteases that mediate degradation of ECM $(68,69)$. It has been reported that human fibrosarcoma cells HT1080 release EVs expressing gelatinases in an active form, while breast cancer cells 8701-BC secrete EVs containing MMP-9 $(68,69)$. The present results demonstrated that BC EVs induced an increase in MMP-9 and MMP-2 secretion in MDA-MB-231 cells. Therefore, EVs may participate in the progression of breast cancer.

In conclusion, it was demonstrated that $\mathrm{BC}$ EVs promoted migration, invasion and MMP-2 and MMP-9 secretion in MDA-MB-231 cells (Fig. 9). Moreover, BC EVs enhanced migration and invasion via a Src-dependent pathway. Therefore, the present results suggested that EVs may participate in breast cancer progression.

\section{Acknowledgements}

The authors would like to thank Ms. Nora Ruiz and Ms. María de Lourdes-Rojas (LaNSE, Cinvestav-IPN) for their technical assistance.

\section{Funding}

The research was funded by CONACYT (grant no. 255429) and CONACYT-FOSISS (grant no. 261637), Mexico. Grants from CONACYT supported the present study.

\section{Availability of data and materials}

The datasets used and/or analyzed during the present study are available from the corresponding author on reasonable request.

\section{Authors' contributions}

JRR performed the majority of experiments. EPS, JRR and RTB drafted the paper. ELO and PCR helped with experiments and reviewed/edited the manuscript. EPS, RTB, EMB, COM, FBM, AHT and IEA analyzed and validated data, and reviewed part of the manuscript. EPS and RTB coordinated the study and wrote the manuscript. All authors read and approved the final manuscript.

\section{Ethics approval and consent to participate}

All studied participants provided signed informed consent, and the protocol was approved by the ethics committee of the First October Regional Hospital-ISSSTE (approval no. 121.2016), and was conducted in accordance with the Declaration of Helsinki.

\section{Patient consent for publication}

Not applicable.

\section{Competing interests}

The authors declare that they have no competing interests.

\section{References}

1. Samavat $\mathrm{H}$ and Kurzer MS: Estrogen metabolism and breast cancer. Cancer Lett 356 (2 Pt A): 231-243, 2015.

2. Siegel RL, Miller KD and Jemal A: Cancer Statistics, 2017. CA Cancer J Clin 67: 7-30, 2017.

3. Ruiz R, Herrero C, Strasser-Weippl K, Touya D, St Louis J, Bukowski A and Goss PE: Epidemiology and pathophysiology of pregnancy-associated breast cancer: A review. Breast 35: 136-141, 2017.

4. Nishimura $\mathrm{R}$ and Arima $\mathrm{N}$ : Is triple negative a prognostic factor in breast cancer? Breast Cancer 15: 303-308, 2008.

5. Perou CM, Sørlie T, Eisen MB, van de Rijn M, Jeffrey SS, Rees CA, Pollack JR, Ross DT, Johnsen H, Akslen LA, et al: Molecular portraits of human breast tumours. Nature 406: 747-752, 2000

6. Sørlie T, Perou CM, Tibshirani R, Aas T, Geisler S, Johnsen H, Hastie T, Eisen MB, van de Rijn M, Jeffrey SS, et al: Gene expression patterns of breast carcinomas distinguish tumor subclasses with clinical implications. Proc Natl Acad Sci USA 98: 10869-10874, 2001.

7. Raposo G and Stoorvogel W: Extracellular vesicles: Exosomes, microvesicles, and friends. J Cell Biol 200: 373-383, 2013.

8. Théry C, Zitvogel L and Amigorena S: Exosomes: Composition, biogenesis and function. Nat Rev Immunol 2: 569-579, 2002.

9. Skotland T, Sandvig K and Llorente A: Lipids in exosomes: Current knowledge and the way forward. Prog Lipid Res 66: 30-41, 2017.

10. Kelleher RJ Jr, Balu-Iyer S, Loyall J, Sacca AJ, Shenoy GN, Peng P, Iyer V, Fathallah AM, Berenson CS, Wallace PK, et al: Extracellular vesicles present in human ovarian tumor microenvironments induce a phosphatidylserine-dependent arrest in the T-cell signaling cascade. Cancer Immunol Res 3: 1269-1278, 2015.

11. Lima LG, Chammas R, Monteiro RQ, Moreira ME and Barcinski MA: Tumor-derived microvesicles modulate the establishment of metastatic melanoma in a phosphatidylserine-dependent manner. Cancer Lett 283: 168-175, 2009.

12. Lea J, Sharma R, Yang F, Zhu H, Ward ES and Schroit AJ: Detection of phosphatidylserine-positive exosomes as a diagnostic marker for ovarian malignancies: A proof of concept study. Oncotarget 8: 14395-14407, 2017.

13. Sharma R, Huang X, Brekken RA and Schroit AJ: Detection of phosphatidylserine-positive exosomes for the diagnosis of early-stage malignancies. Br J Cancer 117: 545-552, 2017.

14. Kanada M, Bachmann MH and Contag CH: Signaling by extracellular vesicles advances cancer hallmarks. Trends Cancer 2: 84-94, 2016.

15. Dourado MR, Korvala J, Åström P, De Oliveira CE, Cervigne NK, Mofatto LS, Campanella Bastos D, Pereira Messetti AC, Graner E, Paes Leme AF, et al: Extracellular vesicles derived from cancer-associated fibroblasts induce the migration and invasion of oral squamous cell carcinoma. J Extracell Vesicles 8: $1578525,2019$.

16. Au Yeung CL, Co NN, Tsuruga T, Yeung TL, Kwan SY, Leung CS, Li Y, Lu ES, Kwan K, Wong KK, et al: Exosomal transfer of stroma-derived miR21 confers paclitaxel resistance in ovarian cancer cells through targeting APAF1. Nat Commun 7: 11150, 2016.

17. Baran J, Baj-Krzyworzeka M, Weglarczyk K, Szatanek R, Zembala M, Barbasz J, Czupryna A, Szczepanik A and Zembala M: Circulating tumour-derived microvesicles in plasma of gastric cancer patients. Cancer Immunol Immunother 59: 841-850, 2010.

18. Galindo-Hernandez O, Villegas-Comonfort $\mathrm{S}$, Candanedo $\mathrm{F}$ González-Vázquez MC, Chavez-Ocaña S, Jimenez-Villanueva X, Sierra-Martinez M and Salazar EP: Elevated concentration of microvesicles isolated from peripheral blood in breast cancer patients. Arch Med Res 44: 208-214, 2013.

19. Zhao Z, Fan J, Hsu YS, Lyon CJ, Ning B and Hu TY: Extracellular vesicles as cancer liquid biopsies: From discovery, validation, to clinical application. Lab Chip 19: 1114-1140, 2019.

20. Egeblad M and Werb Z: New functions for the matrix metalloproteinases in cancer progression. Nat Rev Cancer 2: 161-174, 2002 . 
21. Sternlicht MD and Werb Z: How matrix metalloproteinases regulate cell behavior. Annu Rev Cell Dev Biol 17: 463-516, 2001.

22. Coussens LM, Fingleton B and Matrisian LM: Matrix metalloproteinase inhibitors and cancer: Trials and tribulations. Science 295: 2387-2392, 2002.

23. McCawley LJ and Matrisian LM: Matrix metalloproteinases: Multifunctional contributors to tumor progression. Mol Med Today 6: 149-156, 2000.

24. DeMali KA, Wennerberg K and Burridge K: Integrin signaling to the actin cytoskeleton. Curr Opin Cell Biol 15: 572-582, 2003

25. Wozniak MA, Modzelewska K, Kwong L and Keely PJ: Focal adhesion regulation of cell behavior. Biochim Biophys Acta 1692: 103-119, 2004

26. Parsons JT, Martin KH, Slack JK, Taylor JM and Weed SA Focal adhesion kinase: A regulator of focal adhesion dynamics and cell movement. Oncogene 19: 5606-5613, 2000.

27. Schlaepfer DD, Hauck CR and Sieg DJ: Signaling through focal adhesion kinase. Prog Biophys Mol Biol 71: 435-478, 1999.

28. Serna-Marquez N, Villegas-Comonfort S, Galindo-Hernandez O, Navarro-Tito N, Millan A and Salazar EP: Role of LOXs and COX-2 on FAK activation and cell migration induced by linoleic acid in MDA-MB-231 breast cancer cells. Cell Oncol (Dordr) 36 65-77, 2013

29. Schaller MD: Biochemical signals and biological responses elicited by the focal adhesion kinase. Biochim Biophys Acta 1540: 1-21, 2001

30. Zhao J and Guan JL: Signal transduction by focal adhesion kinase in cancer. Cancer Metastasis Rev 28: 35-49, 2009.

31. Parsons JT: Focal adhesion kinase: The first ten years. J Cell Sci 116: 1409-1416, 2003

32. Schaller MD, Hildebrand JD and Parsons JT: Complex formation with focal adhesion kinase: A mechanism to regulate activity and subcellular localization of Src kinases. Mol Biol Cell 10 3489-3505, 1999.

33. Thery C, Amigorena S, Raposo G and Clayton A: Isolation and characterization of exosomes from cell culture supernatants and biological fluids. Curr Protoc Cell Biol 30: 3.22.1-3.22.29, 2006.

34. Galindo-Hernandez O, Gonzales-Vazquez C, Cortes-Reynosa P, Reyes-Uribe E, Chavez-Ocaña S, Reyes-Hernandez O, Sierra-Martinez M and Salazar EP: Extracellular vesicles from women with breast cancer promote an epithelial-mesenchymal transition-like process in mammary epithelial cells MCF10A Tumour Biol 36: 9649-9659, 2015.

35. Kawamoto T, Ohga N, Akiyama K, Hirata N, Kitahara S, Maishi N, Osawa T, Yamamoto K, Kondoh M, Shindoh M, et al: Tumor-derived microvesicles induce proangiogenic phenotype in endothelial cells via endocytosis. PLoS One 7: e34045, 2012.

36. Ke Z, Lin H, Fan Z, Cai TQ, Kaplan RA, Ma C, Bower KA, Shi $\mathrm{X}$ and Luo J: MMP-2 mediates ethanol-induced invasion of mammary epithelial cells over-expressing ErbB2. Int J Cancer 119: 8-16, 2006.

37. Park MJ, Park IC, Hur JH, Rhee CH, Choe TB, Yi DH, Hong SI and Lee SH: Protein kinase $\mathrm{C}$ activation by phorbol ester increases in vitro invasion through regulation of matrix metalloproteinases/tissue inhibitors of metalloproteinases system in D54 human glioblastoma cells. Neurosci Lett 290: 201-204, 2000.

38. Muralidharan-Chari V, Clancy JW, Sedgwick A and D'Souza-Schorey C: Microvesicles: Mediators of extracellular communication during cancer progression. J Cell Sci 123: 1603-1611, 2010.

39. Hanke JH, Gardner JP, Dow RL, Changelian PS, Brissette WH, Weringer EJ, Pollok BA and Connelly PA: Discovery of a novel, potent, and Src family-selective tyrosine kinase inhibitor. Study of Lck- and FynT-dependent T cell activation. J Biol Chem 271: 695-701, 1996.

40. Bays JL and DeMali KA: Vinculin in cell-cell and cell-matrix adhesions. Cell Mol Life Sci 74: 2999-3009, 2017.

41. Diamant M,Nieuwland R, Pablo RF, Sturk A, Smit JW andRadder JK Elevated numbers of tissue-factor exposing microparticles correlate with components of the metabolic syndrome in uncomplicated type 2 diabetes mellitus. Circulation 106: 2442-2447, 2002.

42. Gupta GP and Massagué J: Cancer metastasis: Building a framework Cell 127: 679-695, 2006.

43. Becker A, Thakur BK, Weiss JM, Kim HS, Peinado H and Lyden D: Extracellular vesicles in cancer: Cell-to-cell mediators of metastasis. Cancer Cell 30: 836-848, 2016.

44. Yáñez-Mó M, Siljander PR, Andreu Z, Zavec AB, Borràs FE, Buzas EI, Buzas K, Casal E, Cappello F, Carvalho J, et al: Biological properties of extracellular vesicles and their physiological functions. J Extracell Vesicles 4: 27066, 2015.
45. Maas SLN, Breakefield XO and Weaver AM: Extracellular vesicles: Unique intercellular delivery vehicles. Trends Cell Biol 27: 172-188, 2017.

46. Lin R, Wang S and Zhao RC: Exosomes from human adipose-derived mesenchymal stem cells promote migration through Wnt signaling pathway in a breast cancer cell model. Mol Cell Biochem 383: $13-20,2013$

47. Luga V and Wrana JL: Tumor-stroma interaction: Revealing fibroblast-secreted exosomes as potent regulators of Wnt-planar cell polarity signaling in cancer metastasis. Cancer Res 73 6843-6847, 2013

48. O'Brien K, Rani S, Corcoran C, Wallace R, Hughes L, Friel AM, McDonnell S, Crown J, Radomski MW and O'Driscoll L: Exosomes from triple-negative breast cancer cells can transfer phenotypic traits representing their cells of origin to secondary cells. Eur J Cancer 49: 1845-1859, 2013.

49. Shtam T, Naryzhny S, Samsonov R, Karasik D, Mizgirev I, Kopylov A, Petrenko E, Zabrodskaya Y, Kamyshinsky R, Nikitin D, et al: Plasma exosomes stimulate breast cancer metastasis through surface interactions and activation of FAK signaling. Breast Cancer Res Treat 174: 129-141, 2019.

50. Li XJ, Ren ZJ, Tang JH and Yu Q: Exosomal microRNA miR-1246 promotes cell proliferation, invasion and drug resistance by targeting CCNG2 in breast cancer. Cell Physiol Biochem 44: 1741-1748, 2017.

51. DeRita RM, Zerlanko B, Singh A, Lu H, Iozzo RV, Benovic JL and Languino LR: c-Src, insulin-like growth factor I receptor, G-protein-coupled receptor kinases and focal adhesion kinase are enriched into prostate cancer cell exosomes. J Cell Biochem 118: 66-73, 2017.

52. Mineo M, Garfield SH, Taverna S, Flugy A, De Leo G, Alessandro R and Kohn EC: Exosomes released by K562 chronic myeloid leukemia cells promote angiogenesis in a Src-dependent fashion. Angiogenesis 15: 33-45, 2012.

53. Naito Y, Yoshioka Y, Yamamoto $Y$ and Ochiya T: How cancer cells dictate their microenvironment: Present roles of extracellular vesicles. Cell Mol Life Sci 74: 697-713, 2017.

54. Meckes DG Jr, Shair KH, Marquitz AR, Kung CP, Edwards RH and Raab-Traub N: Human tumor virus utilizes exosomes for intercellular communication. Proc Natl Acad Sci USA 107: 20370-20375, 2010.

55. Keller S, König AK, Marmé F, Runz S, Wolterink S, Koensgen D, Mustea A, Sehouli J and Altevogt P: Systemic presence and tumor-growth promoting effect of ovarian carcinoma released exosomes. Cancer Lett 278: 73-81, 2009.

56. Bergen K, Mobarrez F, Jörneskog G, Wallén H and Tehrani S: Phosphatidylserine expressing microvesicles in relation to microvascular complications in type 1 diabetes. Thromb Res 172: 158-164, 2018

57. Parsons JT and Parsons SJ: Src family protein tyrosine kinases: Cooperating with growth factor and adhesion signaling pathways. Curr Opin Cell Biol 9: 187-192, 1997.

58. Egan C, Pang A, Durda D, Cheng HC, Wang JH and Fujita DJ: Activation of Src in human breast tumor cell lines: Elevated levels of phosphotyrosine phosphatase activity that preferentially recognizes the Src carboxy terminal negative regulatory tyrosine 530. Oncogene 18: 1227-1237, 1999.

59. Kreger BT, Dougherty AL, Greene KS, Cerione RA and Antonyak MA: Microvesicle cargo and function changes upon induction of cellular transformation. J Biol Chem 291: 19774-19785, 2016.

60. Chen IH, Xue L, Hsu CC, Paez JS, Pan L, Andaluz H, Wendt MK, Iliuk AB, Zhu JK and Tao WA: Phosphoproteins in extracellular vesicles as candidate markers for breast cancer. Proc Natl Acad Sci USA 114: 3175-3180, 2017.

61. Owen JD, Ruest PJ, Fry DW and Hanks SK: Induced focal adhesion kinase (FAK) expression in FAK-null cells enhances cell spreading and migration requiring both auto- and activation loop phosphorylation sites and inhibits adhesion-dependent tyrosine phosphorylation of Pyk2. Mol Cell Biol 19: 4806-4818, 1999.

62. Salazar EP and Rozengurt E: Src family kinases are required for integrin-mediated but not for $\mathrm{G}$ protein-coupled receptor stimulation of focal adhesion kinase autophosphorylation at Tyr-397. J Biol Chem 276: 17788-17795, 2001.

63. Navarro-Tito N, Robledo T and Salazar EP: Arachidonic acid promotes FAK activation and migration in MDA-MB-231 breast cancer cells. Exp Cell Res 314: 3340-3355, 2008.

64. Navarro-Tito N, Soto-Guzman A, Castro-Sanchez L, Martinez-Orozco R and Salazar EP: Oleic acid promotes migration on MDA-MB-231 breast cancer cells through an arachidonic acid-dependent pathway. Int J Biochem Cell Biol 42: 306-317, 2010. 
65. Soto-Guzman A, Robledo T, Lopez-Perez M and Salazar EP: Oleic acid induces ERK1/2 activation and AP-1 DNA binding activity through a mechanism involving Src kinase and EGFR transactivation in breast cancer cells. Mol Cell Endocrinol 294: 81-91, 2008.

66. Hoshino A, Costa-Silva B, Shen TL, Rodrigues G, Hashimoto A Tesic Mark M, Molina H, Kohsaka S, Di Giannatale A, Ceder S, et al: Tumour exosome integrins determine organotropic metastasis. Nature 527: 329-335, 2015.

67. Hotary K, Li XY, Allen E, Stevens SL and Weiss SJ: A cancer cell metalloprotease triad regulates the basement membrane transmigration program. Genes Dev 20: 2673-2686, 2006.

68. Dolo V, Ginestra A, Cassarà D, Violini S, Lucania G, Torrisi MR, Nagase H, Canevari S, Pavan A and Vittorelli ML: Selective localization of matrix metalloproteinase 9 , betal integrins, and human lymphocyte antigen class I molecules on membrane vesicles shed by $8701-\mathrm{BC}$ breast carcinoma cells. Cancer Res 58 : 4468-4474, 1998.
69. Ginestra A, Monea S, Seghezzi G, Dolo V, Nagase H, Mignatti P and Vittorelli ML: Urokinase plasminogen activator and gelatinases are associated with membrane vesicles shed by human HT1080 fibrosarcoma cells. J Biol Chem 272: 17216-17222, 1997.

(i) This work is licensed under a Creative Common Attribution-NonCommercial-NoDerivatives 4.0 International (CC BY-NC-ND 4.0) License. 